\title{
COMPUTER USE AND THE U.S. WAGE DISTRIBUTION, 1984-2003
}

\author{
Robert G. Valletta \\ Federal Reserve Bank of San Francisco
}

October 2006

Working Paper 2006-34

http://www.frbsf.org/publications/economics/papers/2006/wp06-34k.pdf

\begin{abstract}
The views in this paper are solely the responsibility of the authors and should not be interpreted as reflecting the views of the Federal Reserve Bank of San Francisco or the Board of Governors of the Federal Reserve System. This paper was produced under the auspices for the Center for the Study of Innovation and Productivity within the Economic Research Department of the Federal Reserve Bank of San Francisco.
\end{abstract}




\title{
COMPUTER USE AND THE U.S. WAGE DISTRIBUTION, 1984-2003
}

\author{
Robert G. Valletta* \\ Federal Reserve Bank of San Francisco \\ 101 Market Street \\ San Francisco, CA 94105-1579 USA \\ Phone: (415) 974-3345 \\ Fax: (415) 977-4084 \\ email: rob.valletta@sf.frb.org
}

first version: May 2004

this version: October 2006

\begin{abstract}
Given past estimates of wage increases associated with workplace computer use and higher usage rates among more skilled workers, the diffusion of computers has been interpreted as a mechanism for skill-biased technological change and consequent widening of the earnings distribution. I investigate this link by testing for direct effects of rising computer use on the distribution of wages in the United States. Analysis of data from the periodic CPS computer use supplements over the years 1984-2003 reveals that the positive association between workplace computer use and wages declines at higher skill levels, with the notable exception of a higher return to computer use for highly educated workers that emerged after 1997 . Over my complete sample frame, however, the net association between rising computer use and the distribution of wages was quite limited. For broad groups defined by educational attainment, rising computer use was associated with rising between-group inequality that was offset by falling within-group inequality, suggesting that computers have exerted a "leveling" rather than a "polarizing" effect on wages.
\end{abstract}

Keywords: wages, computers, technological change, inequality JEL code: J31

* I thank Jaclyn Hodges and Geoffrey MacDonald for outstanding research assistance. I also thank Mary Daly, Mark Doms, Ellen Hanak, Ethan Lewis, Sabrina Pabilonia, and especially Joydeep Roy for helpful comments on earlier versions of this paper, along with seminar participants at UC Santa Cruz, the Federal Reserve System 2004 Applied Microeconomics Conference, the 2005 Econometric Society Winter Meetings, and the University of British Columbia. The author is solely responsible for any errors and for the views expressed in this paper, which should not be attributed to the Federal Reserve Bank of San Francisco or the Federal Reserve System. 


\section{COMPUTER USE AND THE U.S. WAGE DISTRIBUTION, 1984-2003}

\section{INTRODUCTION}

The introduction and widespread diffusion of desktop computers has transformed the American workplace during the past few decades. Between 1984 and 2003, the percentage of individuals who directly use a computer at work more than doubled, increasing from about 25 percent to nearly 57 percent. This steady evolution has transformed the way work is done, as workers and firms increasingly rely on computers to perform routine repetitive tasks and enhance worker performance on nonroutine analytic tasks (Autor, Levy, and Murnane 2003).

A growing body of evidence suggests that computers and the skills associated with their use have altered the wage structure, in particular by increasing relative demand and wages for college-educated workers (Krueger 1993; Autor, Katz, and Krueger 1998; Autor, Levy, and Murnane 2003). Such findings are consistent with the view that the diffusion of computers and related technologies is associated with "skill-biased technological change" (SBTC), which increases the relative wages of skilled workers. However, these findings have provoked substantial disagreement from scholars who argue that computers do not directly affect wages (DiNardo and Pischke 1997) or that changes in the U.S. wage distribution since the 1970s are not consistent with common theoretical and empirical formulations of SBTC (Card and DiNardo 2003, Beaudry and Green 2005, Lemieux 2006).

In the present paper, I extend this literature by estimating the direct association between rising computer use and the distribution of wages in the United States. The empirical analyses in this paper rely on the Computer Use Supplements to the U.S. Current Population Survey (CPS), available for selected years over the period 1984-2003. After describing the patterns in computer 
use and inequality over time, the empirical work proceeds by estimating the conditional correlation between computer use and wages (i.e., the "return" to computer use). The results of OLS and quantile regressions suggest that the return to computer use generally declines at higher skill levels, with the exception of a sharp increase in the relative return to computer use for highly educated workers after 1997.

Further analyses that account for combined price and quantity effects using the semiparametric density decomposition technique of DiNardo, Fortin, and Lemieux (1996) reveal that rising computer use had a limited direct impact on the overall U.S. wage structure during my sample frame. Rising computer use was associated with rising inequality between collegeeducated and high-school educated individuals but falling inequality within these groups, especially for college graduates. Overall, it appears that rising computer use offset the erosion of relative wages in the middle of the distribution, suggesting that personal computers represent a “leveling” technology rather than a "polarizing” technology (Autor, Katz, and Kearney 2006).

\section{COMPUTERS, SKILLS, AND WAGES}

\section{II.A. Inequality Literature}

In the late 1980s and early 1990s, a substantial body of research emerged that examined the underlying causes of an observed increase in U.S. earnings inequality. A leading explanation that emerged from early work was a demand shift favoring skilled workers, arising from an exogenous change in production technology (SBTC). The seminal papers in this area concluded that SBTC played a critical role in the evolution of the U.S. wage structure during the 1970s and 1980s (e.g. Bound and Johnson 1992, Katz and Murphy 1992).

These initial studies did not employ direct measures of SBTC, instead interpreting a 
residual trend in the measured skill premium as a reflection of it. Subsequent researchers have employed more direct measures of changing production technology. In the first investigation of the direct effect of computer use on wages, Krueger (1993) used data from the 1984 and 1989 CPS computer use supplements and found that workers using computers on the job earned about 15-20 percent more than those who did not, conditional on a standard set of wage determinants. His results suggested that rising computer use between 1984 and 1989 accounted for about onehalf of the rising return to education over this period.

Subsequent papers broadened Krueger's focus by investigating the relationship between computers (and other high-tech capital) and relative demand for skilled workers. Using industrylevel data, Autor, Katz, and Krueger (1998) found strong links between the use of computer capital and employment of college-educated workers by industry. Autor, Levy, and Murnane (2003) extended this work by specifying precisely what computers are used for and how they substitute for or complement various worker skills. Their estimated relationship between the adoption of computer technology and shifts in job tasks implies that nearly two-thirds of the increase in relative demand for college-educated workers during the past three decades can be explained by rising workplace computer use. However, they did not test for the relative wage effects of these demand shifts. ${ }^{1}$ Other work has focused on the tendency for capital deepening (including computers) to increase wage gaps when capital and skills are complementary inputs in the aggregate production function (e.g., Krusell et al. 2000).

\footnotetext{
${ }^{1}$ Other papers have used broader measures of new technology. Feenstra and Hanson (1999) used data for 4-digit manufacturing industries and found that investment in computers and other high-tech equipment explains a substantial portion of the wage differences between production and nonproduction workers. Allen (2001) found strong links between returns to schooling at the individual level and various indicators of technological change (measured within 2-digit industries).
} 
By contrast, a number of authors have argued against the SBTC and skill complementarity interpretations of computer use and wages. DiNardo and Pischke (1997) found that workers who use simple office tools such as pencils earn a wage premium similar to that estimated for computer users. They infer from this result that computer use may not have an independent causal impact on wages but instead may reflect unobserved heterogeneity in worker productivity that would generate higher wages for individuals who use computers even in the absence of computer use. Their work relates to a broader strand of research which argues that SBTC accounts for little of the observed changes in the U.S. wage distribution during recent decades. This literature emphasizes the role of alternative considerations such as the decline of unions and the falling real value of the minimum wage (DiNardo, Fortin, and Lemieux 1996, Lee 1999), the timing of increased earnings inequality relative to observed technological change (Card and DiNardo 2002), and the contribution of changing workforce composition to measured within-group inequality (Lemieux 2006).

I add to this literature by directly measuring computer use in assessing the relationship between technological diffusion and changes in the U.S. wage distribution. Before proceeding to the empirical analysis, I first discuss the link between computer use and the distribution of wages in alternative models.

\section{II.B. Computer Adoption and Wages}

Much of the debate over the wage impact of rising computer use has revolved around the question of whether computer adoption induces direct productivity effects for individual workers (Krueger 1993) or instead reflects unobserved heterogeneity in worker skills (DiNardo 1997). As noted in recent research (Borghans and ter Weel 2006, Zoghi and Pabilonia 2005), however, computer use by an individual worker entails capital investment costs (equipment and software) 
for firms and probably an investment cost to workers as well, through the costs of skill acquisition needed for effective use of computers. It is therefore likely that computer use will be associated with higher wages at the level of individual workers or worker groups; this wage gap reflects the increase in productivity required to offset the costs of investment in physical and human capital. ${ }^{2}$

The recent literature on computer capital and wages (Krusell et al. 2000, Autor, Levy, and Murnane 2003, Borghans and ter Weel 2006) has focused on the question of what happens to relative labor demand and the wage distribution when the capital costs of computers $\left(\mathrm{C}^{\mathrm{K}}\right)$ are declining rapidly. Investment costs are typically ignored in this literature. However, if investment costs are important, the declining price of computers will reduce the investment costs required for computer use on the job and expand the set of workers for whom computer use is financially advantageous (i.e., for whom investments in computer use pays net returns to the worker and firm). As such, rising computer use is likely to be associated with rising inequality initially, as the technology is adopted by workers with relatively high returns, but this effect on inequality is likely to dissipate over time as the cost of computers declines and the required productivity returns decline commensurately at the margin.

Moreover, an important alternative to the SBTC view is provided by Beaudry and Green (2003, 2005). For their model of discrete changes in technological opportunities, they specify a production function with two separable components reflecting different modes of organization or production: a longstanding or "traditional” mode and a second, more "modern" mode. In

\footnotetext{
${ }^{2}$ Borghans and ter Weel (2006) developed a stylized model of computer diffusion which implies that firms assign computers to high-wage workers. Although the initial causal link in their model is from wages to computer use rather than vice versa, the introduction of computers raises productivity in their model and, eventually, inequality as well.
} 
conjunction with reasonable assumptions that are supported by data for the United States and Germany, their model implies that an increase in physical capital will reduce the wage gap between skilled and unskilled workers. As they note, these findings are opposite to those implied by the standard SBTC and capital-skill complementarity scenarios, but they are consistent with an economy undergoing a major, discrete change in technological opportunities, such as might be represented by a switch to computer-based technologies. ${ }^{3}$ Given the rising share of computer equipment and software in business investment spending over the past two decades, the finding that rising capital abundance may decrease wage gaps suggests that increases in the use of computer capital may not have contributed to an increase in the skill premium or wage differentials in the United States.

The various theories discussed suggest that the association between rising computer use and the distribution of wages is ambiguous. The remainder of this paper will focus on testing whether rising use of computers in the workplace is more consistent with views based on SBTC and capital-skill complementarity vs. alternatives, through direct examination of the impact of computer use on individual wages and the overall distribution of wages. Given the absence of direct empirical evidence on whether computer use increases productivity for individual workers, the empirical findings below may reflect a causal relationship between computers and individual worker productivity, or they may reflect the influence of unobserved skills that are associated with computer use. Despite this ambiguity, for the sake of simplicity I refer below to the association between wages and computer use as the "return" to computer use.

\footnotetext{
${ }^{3}$ Beaudry, Doms, and Lewis (2006) provide empirical tests that rely on direct measures of computer use at the city level.
} 


\section{DATA SOURCE AND TABULATIONS}

For the empirical work in this paper, I use the School Enrollment and Computer and Internet Use Supplements to the U.S. CPS, conducted in 1984, 1989, 1993, 1997, 2001, and 2003 (referred to below as the "computer use supplements"). In addition to the usual array of monthly CPS questions regarding demographics and employment, supplement respondents were asked about computer use at work, home, and school. Although the exact content of the supplements changed over time (for example, internet use was addressed beginning in 1997), except for minor changes in wording the question regarding computer use at work has been unaltered. For the results reported below, I rely on samples of about 60,000 employed individuals in each survey for the calculation of rates of computer use at work; of these, information on wages and related variables is provided for about one-fourth of the sample (the "outgoing rotation groups;" about 12-14,000 individuals). The analyses are restricted to individuals age 18 to 64 .

Table 1 displays basic descriptive statistics for the pattern of workplace computer use over time (weighted using the CPS supplement weights). Computer use generally increases with skill indicators, notably education and white-collar job status. This relationship is not uniform, however, suggesting that computer use is not simply a proxy for workers' general skill level. Women have noticeably higher computer use rates than men in every year, although as Card and DiNardo (2002) note, this gap declines at higher educational levels (not shown). In addition, computer use generally increases with age, although it tapers off after age 40 in the early sample years (1980s) and after age 54 in all years. The usage pattern by age probably is due to cohort differences in older workers' exposure to computers, which was especially low in earlier sample years, when computers in the workplace were relatively novel.

In percentage terms (relative to initial usage rates), the sharpest increase in computer use 
over time is evident for groups with low initial use, including older workers, part-time workers, blue-collar workers, and workers without a high school degree. However, if the usage gap is measured in percentage points, it has increased over time between high-skill and low-skill workers; for example, the usage gap between individuals with a high school degree and those with a college degree increased from 22.6 percentage points in 1984 to 41.8 percentage points in 2003. Moreover, the diffusion of computer use slowed noticeably after 1993; this can be seen most clearly in Figure 1, which displays usage rates over time for the complete sample and for individuals with a high school or college education.

For the analysis of computer effects on wages, I use hourly wages (recorded as such for hourly workers, and defined as weekly wages divided by usual weekly hours for salaried workers). ${ }^{4}$ As noted above, wage data are available for about one-fourth of the sample. For each set of computer supplement data, the observations with information on wages correspond to a single monthly observation from the CPS monthly outgoing rotation group samples (CPSMORG). The CPS-MORG has been used in numerous studies of rising wage inequality. As argued persuasively by Lemieux (2006), these data are more reliable than leading alternative sources of wage data — notably earnings data from the March CPS — because they provide a less noisy measure of the key variable of interest (compensation per hour).

Figure 2 (Panels A and B) displays several commonly used measures of wage dispersion, for the complete sample and separately for men and women. In these figures, yearly tabulations using the CPS-MORG are compared with the same calculations from the computer supplements, with wages expressed in real terms using the GDP deflator for personal consumption

\footnotetext{
${ }^{4}$ Like Krueger (1993), I deleted observations for individuals earning less than $\$ 1.50$ per hour or more than $\$ 250$ per hour.
} 
expenditures (base year $=2003$ ) and weighted using the earnings supplement weights. The increase in overall wage inequality that has been the subject of voluminous past research is reflected in the growing gap between wages at the $90^{\text {th }}$ and $10^{\text {th }}$ percentiles of the wage distributions for all workers and for men and women separately. Much of the increase in overall inequality occurred in the early 1980s, however, prior to the introduction of the Internet and widespread diffusion of computer networking in the 1990s. ${ }^{5}$ By contrast, the average wage gap between individuals holding at least a college degree and those possessing a high school degree or less (College/HS) increased sharply in the 1980s and then increased noticeably in the late 1990s before falling slightly between 2001 and 2003 (Figure 2, Panel A). Panel B of Figure 2 shows that the pattern in overall wage inequality (p90/p10) was similar for men and women, although the increase in inequality in the 1980s was especially pronounced for women. The two panels of Figure 2 also show that the wage data from the computer supplements largely reproduce the pattern in wage inequality over time from the CPS-MORG, with the notable exception of a sharp increase in the college/high school wage gap in the 2001 supplement data.

Figure 3 depicts inequality in the upper and lower halves of the wage distribution, by displaying the CPS-MORG calculations of the p90/p50 and p50/010 wage ratios separately for men and women. ${ }^{6}$ For both sexes, upper-half wage inequality exhibited a relatively consistent upward trend during the entire sample period, while lower-half inequality rose for men and especially for women during the 1980s then fell (men) or was largely flat (women) during the 1990s.

\footnotetext{
${ }^{5}$ Lemieux (2006) finds similar patterns over time in residual wage inequality from the CPSMORG data, which he argues are inconsistent with SBTC impacts on the wage structure (see also Card and DiNardo 2002).

${ }^{6}$ Corresponding calculations from the CPS computer supplements reveal similar patterns over time; to minimize Figure 3's visual complexity, these tabulations are not displayed.
} 
On net, the tabulations of computer use and wage inequality over time do not point to any clear relationships between the two. Overall inequality (p90/p10) rose most rapidly in the 1980s, when computer diffusion was relatively rapid. However, growing wage inequality in the 1990s was largely restricted to the upper half of the wage distribution, despite continued growth in the computer usage gap between highly skilled and less skilled workers. On the other hand, the college/HS wage gap grew rapidly during the 1980s and late 1990s, perhaps due in part to the growing absolute gap in computer use between individuals with college and high school degrees.

\section{EMPIRICAL ASSOCIATION BETWEEN COMPUTERS AND WAGES}

\section{IV.A. Baseline (OLS) Estimates}

In this section, I provide baseline regression estimates for the conditional association between computer use and wages. ${ }^{7}$ These regressions largely replicate Krueger’s (1993) specification using the 1984 and 1989 computer use supplements (except for slight differences in sample counts). The primary difference is that Krueger measured educational attainment in years, whereas I measure educational attainment according to broad categories (less than high school, high school degree, some college, bachelor's degree, and graduate degree) and use corresponding dummy variables in the regressions. ${ }^{8}$ Results are listed only for the key variables, computer use and educational attainment. The column (i) specification for each year lists the returns to education excluding computer use, while the subsequent two columns for each year

\footnotetext{
${ }^{7}$ Tashiro (2004) examines the association between wages and computer use, focusing on how the return differs according to worker characteristics (including occupation and industry) and the specific computer applications used.

${ }^{8}$ Reliance on educational category dummies is a common approach that accounts for nonlinearities in estimated returns to education. Other control variables are listed at the bottom of the table. Labor market experience is measured as (age - education -6).
} 
add a dummy variable for computer use and interactions between it and the educational dummies.

The coefficient on computer use in columns (ii) ranges from about 0.16 to 0.22 . The appropriate transformation of dummy variable coefficients in logarithmic equations yields a percentage effect of computer use on wages ranging from about 17 to 24 percent. Figure 4 shows the pattern over time in the percentage return to computer use estimated from Table 2; the return peaks in 1993 and then declines somewhat. The same regressions also were run with a set of dummy variables that account for wage differences across 13 major occupational categories. As shown in Figure 4, the inclusion of occupational dummies reduces the estimated return to computer use somewhat, but the effect of computer use remains large (and highly statistically significant in each case) and a similar pattern over time is evident across the two specifications. ${ }^{9}$

One of the key findings from Krueger's (1993) paper is that the return to computer use rises with educational attainment, which is consistent with skill bias in the return to computer use. In his regressions using the 1989 data, the educational interaction accounts for the entire effect of computer use on wages. This result is not replicated when educational attainment is measured in categories. In the column (iii) specifications in Table 2, the return to computer use in 1984 and 1989 is relatively flat or declines with education, with statistically significant or near significant negative interactions obtained for graduate degrees. This divergence of my results from Krueger's arises from the linear restriction imposed by measuring education in years, not from sample differences (which are quite minor in any event). When the column (iii) regressions are re-estimated with the educational categories replaced by attainment in years, the coefficients

\footnotetext{
${ }^{9}$ It is not clear whether occupational controls should be included in a regression intended to capture the conditional correlation between computer use and wages, because the decision to acquire computer skills may be partly reflected in occupational choice.
} 
on the schooling variable and its interaction with computer use are nearly identical to Krueger's estimates. The results for 1993 and 1997 also reveal limited variation in the returns to computer use across educational attainment categories (which in no case are statistically significant).

In contrast to results for the earlier sample years, however, the regressions for 2001 and 2003 reveal higher returns to computer use for college and graduate degree holders than for individuals with less education. This differential is especially large in the 2001 data; its size may be misleading, since it may arise due to the unusually high college/high school wage gap estimated from the 2001 computer supplement data (see Figure 2, Panel A). In the 2003 data, the sample-wide return to computer use is about 17 percent. This return varies from about 14 percent for individuals with less than a high school degree to about 24 percent for college-degree holders. Figure 5 displays the complete set of estimated percentage returns to computer use by educational attainment categories for each of the computer supplement samples (the results are quite similar when the regressions are run separately by educational category). ${ }^{10}$

Separate regressions for men and women (not shown) reveal patterns in the return to computer use over time and across educational categories that are similar to those displayed for the full sample in Table 2. However, in some years a slight positive interaction effect between computer use and educational attainment for men is offset by a negative interaction effect for women. In addition, the positive interaction effect between computer use and educational attainment in 2001 and 2003 (found for the full sample in Table 2) is limited to men.

\footnotetext{
10 These results are largely unchanged when individuals working as teachers are excluded from the sample, except that in the 2001 and 2003 data the return to computer use for individuals holding a bachelor's degree is reduced somewhat relative to the return to computer use for individuals holding a graduate degree. These results also are largely invariant to the inclusion of controls for broad occupational categories, except that the positive interactions between computer use and college/graduate degrees in 2003 are substantially reduced.
} 


\section{IV.B. Returns to Education}

Krueger concluded his analysis of the returns to computer use in the 1984 and 1989 supplement data by assessing the contribution of rising computer use to the increase in returns to education over this period. As noted above, by imposing a linear restriction on the estimated returns to education, Krueger appears to have overstated the degree to which the return to computer use increases with education. However, this has little impact on his overall assessment that rising computer use accounted for a substantial share of the rising returns to education in the 1980s, because the greater growth in computer use among more educated individuals made a larger contribution to rising returns to education than did their estimated higher return to computer use.

In particular, Krueger found that rising computer use accounted for 40-50 percent of the increase in the return to education between 1984 and 1989. My Table 2 results indicate a somewhat smaller contribution of rising computer use to increased returns to education than Krueger found, mainly because my results do not indicate higher returns to computer use for more educated workers. For example, using the column (i) results from Table 2 (transformed to percentage effects), the wage gap between college-educated and high-school educated individuals rose by 11.6 percentage points between 1984 and 1989 . This increase is reduced to 8.0 percentage points when computer use is controlled for in column (ii). The comparison across these two sets of results indicates that rising computer use accounts for 31 percent ((11.68.0)/11.6) of the increased relative return to a college education between 1984 and 1989 . A similar calculation indicates that rising computer use can account for 34.5 percent of the net increase in the return to college over my complete sample frame (between 1984 and 2003). The results are similar when the interactions between computer use and educational attainment (from 
the column (iii) specifications in Table 2) are incorporated.

\section{IV.C. Quantile Regression Results}

The relationship between skill level and returns to computer use can be investigated further using quantile regression, which enables estimation of the conditional impact of individual variables on the value of a dependent variable at specific percentiles of its underlying distribution. Assuming that the observed wage represents a monotonic index for workers' skill sets, quantile regression provides a means for estimating the impact of computer use on wages across the complete distribution of skills. ${ }^{11}$

Table 3 lists coefficient estimates for the impact of computer use on wages at the 0.10 , 0.25, 0.50 (median), 0.75 , and 0.90 percentiles (“quantiles”) of the wage distribution (expressed in natural logs), along with the impact on mean wages (from corresponding OLS regressions). These quantiles were chosen for comparability to past analyses of changes in the U.S. distribution of wages (e.g., Buchinsky 1994). The regressions serve as linear predictors of the value of wages at the specified quantile of the wage distribution. As such, the estimated coefficients in Table 3 represent the approximate percentage association between computer use and the wages of individuals at the specified quantile of the wage distribution; they are estimated conditional on the complete set of other control variables used in the OLS regressions from Table 2, using the pooled sample of men and women.

The results in Table 3 reveal relatively uniform returns to computer use across the conditional wage distribution, with coefficients varying between 0.15 and 0.20 for most quantiles

\footnotetext{
${ }^{11}$ See Buchinsky (1998) for a straightforward description of the quantile estimation framework. I obtain standard errors for the estimated coefficients using the method suggested by Koenker and Bassett (1982).
} 
in most years. ${ }^{12}$ However, the results suggest that the return to computer use is lower at higher wage levels. This pattern is especially pronounced in the upper half of the wage distribution, with a significantly smaller wage increment due to computer use at the $90^{\text {th }}$ percentile than at the $50^{\text {th }}$ percentile in most years. ${ }^{13}$ Moreover, this pattern of lower returns to computer use at higher wage levels is not associated with lower incidence of computer use at higher wage levels: in general, computer use increases substantially with measured wage quantiles (results not shown).

To further account for differences in the return to computer use across skill levels, I estimated quantile regressions by education and experience group. I first divided the sample into individuals possessing a high school degree or less and those possessing a college or graduate degree; within these educational categories, I divided the sample into four groups defined by (potential) labor market experience, ranging from recently entered cohorts (0-5 years experience) to highly experienced workers (31 or more years of experience). The complete regression results are provided in Appendix Tables 1 and 2; they indicate a significant wage increase associated with computer use for most education and experience groups. Figure 6 displays the estimated coefficients on computer use for selected education/experience groups in different years, for the college sample in Panel A and the high school sample in Panel B. The groups and years displayed were chosen to illustrate the broad patterns evident for the complete set of groups in the appendix tables. The finding from the full sample (Table 3) of lower returns to computer use at higher wage levels is largely restricted to individuals possessing a college or graduate degree. By contrast, the return to computer use is more uniformly distributed for individuals possessing a

\footnotetext{
${ }^{12}$ Quantile regressions for separate samples of men and women yielded results similar to those for the pooled sample (not shown).

${ }^{13}$ Separate inter-quantile regressions revealed that computer use is associated with a reduction in the 90-10 and 90-50 wage spreads, with estimates significant at better than the 1 percent level in most years.
} 
high school degree or less. In the high school sample, the return to computer use declines across quantiles for some experience groups in some years but is relatively flat or increases across quantiles for other group/year combinations.

Overall, the OLS and quantile wage regressions suggest that rising computer use can account for some of the rising return to education in the 1980s and 1990s, but more generally the wage increase associated with computer use serves to reduce observed wage gaps, especially for college-educated workers. The conflicting nature of these results suggests the need for a more comprehensive technique to assess the impact of rising computer use on the wage distribution.

\section{DISTRIBUTIONAL EFFECTS OF RISING COMPUTER USE}

The results from the previous sections indicate that the extent of computer use generally rises with observable skill indicators, while the return to computer use generally declines at higher levels of skills (wages). These quantity and price effects can be combined to assess the relationship between rising computer use and the complete distribution of wages, using the conditional density estimation technique of DiNardo, Fortin, and Lemieux (DFL; 1996). The procedure is implemented by reweighting the wage data based on the observed distribution of computer use in the analysis year (e.g., 2003) relative to computer use in a base year (e.g., 1984). Intuitively, to adjust the 2003 wage distribution to the 1984 structure of computer use, less weight must be placed on computer users in the 2003 data, since the incidence of computer use was lower in 1984 than in 2003. On average, the weight assigned to computer users in the 2003 data is reduced by the relative proportion of computer users in 1984 vs. 2003, yielding a counterfactual distribution of wages in 2003 as if computer use had remained at its 1984 level. The movement between the counterfactual and actual distribution identifies the impact of rising 
computer use.

The specific implementation is performed in a conditional framework, where the relative probabilities of computer use in 1984 and 2003 are estimated using a logit model that includes the complete set of other covariates from the earlier wage regressions; Appendix A provides a precise description of this procedure. In this conditional framework, the counterfactual question being posed is: what would the distribution of wages look like in 2003 if the level and pattern of computer use, conditional on individual attributes, was the same in 2003 as it was in 1984 (and workers were otherwise paid according to the wage structure prevailing in 2003)?

In addition to adjusting for the overall change in computer use, this conditioning exercise accounts for changes over time in the distribution of variables that jointly affect computer use and wages. For example, rising computer use has both a direct effect on wages and an indirect effect through its positive association with educational attainment, which also is associated with higher wages. The DFL procedure properly limits the estimated distributional impact of rising computer use to its direct effect only, by conditioning out the rise in educational attainment that occurred between 1984 and 2003; this is analogous to the conditional estimation of the return to computer use in the wage regressions reported earlier. On the other hand, if the positive association between educational attainment and computer use strengthened or weakened between 1984 and 2003, less weight would be assigned to highly educated computer users in the counterfactual (comparison) distribution, thereby altering the estimated distributional impact of rising computer use. The results of the DFL procedure can be examined in visual form, by comparing plots of the observed and counterfactual densities of wages, or through comparison of 
quantitative measures of wage dispersion in the observed and counterfactual cases. ${ }^{14}$

The results of the counterfactual estimation of the 2003 wage density are summarized in Figure 7 (full sample only) and Tables 4-6 (full sample, men and women separately); for comparability over time, wages are expressed in real terms (2003 dollars), using the GDP deflator for personal consumption expenditures. Figure 7 displays kernel density estimates of three distributions of log wages: the unadjusted wage distributions in 1984 and 2003, plus the counterfactual 2003 wage distribution. The impact of rising computer use is reflected in the movement between the counterfactual 2003 distribution, which reflects the level and pattern in computer use of 1984, and the actual 2003 distribution. The figure shows some movement in density mass from the middle portion of the counterfactual 2003 distribution to the upper portion of the actual 2003 distribution, suggesting that rising computer use may have increased wage dispersion.

Because the distributional changes cannot be interpreted precisely in graphical form, I present the kernel density graphs for the full sample only and mostly focus attention on the quantitative dispersion measures listed in Tables 4-6. These tables list separate results for the full sample, men, and women, respectively. Each set is then divided into three sets of two columns, which display results by educational attainment (all, college or graduate degree, and high school degree or less); this enables a standard comparison of between-group and withingroup inequality. For each pair of columns, the first lists the total change in the dispersion measure, while the second column lists the portion of the total change attributable to rising

\footnotetext{
14 The CPS supplement weights are used for calculation of the unadjusted distributions; these weights are modified by the counterfactual weights to estimate the adjusted distributions (see Appendix A). See DiNardo, Fortin, and Lemieux (1996), Daly and Valletta (2006), or Lemieux (2006) for additional discussion and applications.
} 
computer use, conditional on the distribution of individual attributes. Numbers in brackets indicate the percentage of the total change explained by the rising level and changing pattern of computer use.

To precisely characterize the impact of changing computer use on the wage distribution, I list results for median (real) wages plus a variety of standard dispersion measures. These include parametric summary measures such as the standard deviation, Gini and Theil indices, and mean logarithmic deviation, along with measures of selected percentile gaps and the average wage gap between individuals holding a college degree and those holding a high school degree. ${ }^{15}$

The results in Table 4 indicate that rising computer use had a limited direct effect on overall inequality but noticeable effects on inequality among different groups and in different parts of the distribution. Rising computer use is associated with rising real wages for most workers: it account for over 40 percent of the increase in real median earnings between 1984 and 2003 (columns 1-2). However, rising computer use generally contributed very little, or made a counterfactual contribution, to the overall increase in wage dispersion over this period (columns 1 and 2). In particular, rising computer use generally offset or did not affect the increase in inequality measured by the standard deviation, Gini and Theil coefficients, and the mean log deviation. On the other hand, rising computer use had a counterfactual impact on dispersion in the upper and lower halves of the wage distribution, offsetting rising dispersion in the upper half but substantially offsetting declining dispersion in the lower half. On net, the latter effect dominates, and about one-third of the overall increase in the gap between earners at

15 Calculations for the median, standard deviation, and percentile differences are all based on the natural log of hourly wages and as such are expressed in percentage terms. Calculations for the Gini and Theil coefficients, the mean log deviation, and the college vs. high school gap are based on wages expressed in levels rather than logs. 
the $90^{\text {th }}$ and $10^{\text {th }}$ percentiles is explained by rising computer use. Rising computer use also explains a little over one-fourth of the increased wage gap between holders of college and high school degrees (roughly consistent with Krueger 1993 and my results in section IV.B).

Underlying the results for the overall sample in columns (1)-(2) of Table 4 are differences in the results across groups defined by educational attainment, listed in columns (3)-(6). Rising computer use is associated with a substantial share of the increase in median wages for collegeeducated individuals (columns 3-4), but it is uniformly associated with a substantial offset to the measured increase in wage dispersion for this group. In particular, the impact of rising computer use in column (4) is uniformly negative and large relative to the observed increase in dispersion according to each measure. By contrast, rising computer use had largely neutral effects on wage dispersion among individuals holding a high school degree or less, despite accounting for a large share (about one-third) of the increase in median wages for this group. These results are broadly consistent with the findings from the quantile regressions displayed in Figure 6 and the appendix tables, which indicated that the return to computer use declines at higher wage quantiles within the college-educated sample but is relatively uniform across wage quantiles for individuals holding a high school degree or less. Moreover, the DFL results indicate that the increase in computer use among high wage earners in general was not large enough to offset the wageequalizing effect of the returns to computer use within the college-educated group.

The results for men and women separately, displayed in Tables 5 and 6, are qualitatively similar to the pooled results in Table 4. For both sexes, rising computer use is associated with neutral or offsetting effects on the observed rise in overall inequality (Tables 5 and 6, columns 12). Moreover, rising computer use is associated with rising inequality in the bottom half of the distribution for both groups, offsetting the observed decline for men but accounting for a 
substantial share of the observed increase for women (Tables 5 and 6, p50/p10 gap, columns 1-

2). Rising computer use generally is associated with declining dispersion among collegeeducated individuals of both sexes (Tables 5 and 6, columns 3-4), and it had largely neutral or mixed effects on dispersion among individuals holding a high school degree or less (columns 56). One notable difference between men and women is evident in the association between rising computer use and the college/high school wage gap. For men, rising computer use accounts for about one-fourth of a substantial increase in this gap, while for women the increase in this gap was smaller and rising computer use is largely unassociated with the increase. In addition, rising computer use is associated with a substantial share of the overall increase in the p90/p10 gap and the p75/p25 gap for men (Table 5, columns 1-2), although these effects are offset in the pooled sample of men and women by a negative association between rising computer use and these percentile gaps for women (Table 6, columns 1-2).

In additional analyses not displayed, I investigated whether these patterns vary across different sub-samples of the data. I focused in particular on comparing changes from 1984 to 1993 with those from 1993 to 2003; these sub-periods are distinguished by a relatively large increase in inequality in the earlier period and faster productivity growth (often associated with technological change) in the later period. The qualitative results were quite similar across these two periods, with a substantial contribution of rising computer use to the college/high school earnings gap offset by reduced dispersion associated with rising computer use among collegeeducated individuals. 


\section{CONCLUSIONS}

This manuscript has examined the question of whether rising computer use has been a mechanism for skill-biased technological change (SBTC) that has increased wage dispersion in the United States. Despite the voluminous literature that treats computers as a skill-biased technology, recent theoretical and empirical analyses suggest that increased reliance on computer-based technologies may not increase measured wage inequality (e.g., Card and DiNardo 2002, Beaudry and Green 2003, 2005). The general patterns in computer diffusion and wage returns uncovered in this paper are consistent with widespread applicability of computer skills across the wage distribution and over time. Moreover, the return to computer use generally declines at higher skill levels, suggesting that rising computer use per se was not a source of SBTC that widened the earnings distribution between 1984 and 2003.

This interpretation of rising computer use was reinforced by an analysis of its impact on the complete distribution of wages. In particular, conditional on the distribution of worker characteristics that affect wages, the growth in computer use between 1984 and 2003 had a limited impact on overall inequality. Underlying this overall effect of rising computer use was its contribution to rising inequality across broad education groups that was offset by its contribution to falling inequality within these groups (primarily for individuals holding college degrees). Moreover, rising computer use had counterfactual and divergent effects on the upper and lower portions of the wage distribution, offsetting growing wage dispersion between the middle and top but also offsetting falling wage dispersion between the bottom and middle.

These findings suggest that workers in the middle portion of the wage distribution responded to growing demand for computer skills by acquiring those skills as a means for offsetting erosion of their wages relative to wages of individuals near the top and the bottom of 
the wage distribution. This suggests in turn that over time, rising computer use has represented a "leveling” technology rather than a skill-biased or "polarizing” technology (as argued by Autor, Katz, and Kearney 2006). This interpretation of computers as a leveling technology is consistent with the results of Weinberg (2000), who found that rising computer use increased the relative demand for female vs. male workers during the years 1970-1994 (and presumably contributed to the declining male/female wage gap during the latter part of this period).

My conclusions are based on the observable correlations between computer use and wages, without any accounting for unobservable characteristics of workers that jointly affect computer adoption and wages. This is a shortcoming that subsequent research might address. For now, my results pose a challenge to the SBTC view, suggesting limited direct effects of rising computer use on the overall distribution of wages. Bresnahan (1999) and Autor and Katz (1999) have noted that the primary wage effects of technology shifts may be indirect, occurring at the organizational level or in the broader market for skills and altering the wages of individuals who do not use computers in addition to those who do. This argument is persuasive a priori. However, while existing research has uncovered a close relationship between computer use and quantities of labor used by broad type (e.g., Autor, Levy, and Murnane 2003), direct evidence regarding the impact of such shifts on the overall wage structure has remained elusive. 


\section{References}

Allen, Steven. 2001. “Technology and the Wage Structure.” Journal of Labor Economics 19 (2, April): 440-483.

Autor, David H., and Lawrence F. Katz. 1999. "Changes in the Wage Structure and Earnings Inequality.” In O. Ashenfelter and D. Card, eds., Handbook of Labor Economics, Volume 3. Amsterdam: Elsevier.

Autor, David H., Lawrence F. Katz, and Alan B. Krueger. 1998. "Computing Inequality: Have Computers Changed the Labor Market?” Quarterly Journal of Economics 113 (4, Nov.): 1169-1213.

Autor, David H., Lawrence F. Katz, and Melissa S. Kearney. 2006. “The Polarization of the U.S. Labor Market.” NBER Working Paper 11986, January.

Autor, David H., Frank Levy, and Richard J. Murnane. 2003. "The Skill Content of Recent Technological Change: An Empirical Exploration.” Quarterly Journal of Economics 118 (4, Nov.): 1279-1333.

Beaudry, Paul, Mark Doms, and Ethan Lewis. 2006. "Endogenous Skill Bias in Technology Adoption: City-Level Evidence from the IT Revolution.” FRBSF Working Paper 200624, August.

Beaudry, Paul, and David A. Green. 2003. "Wages and Employment in the United States and Germany: What Explains the Differences?” American Economic Review 93 (3, June): 573-602

Beaudry, Paul, and David A. Green. 2005. "Changes in U.S. Wages 1976-2000: Ongoing Skill Bias or Major Technological Change?” Journal of Labor Economics 23(3, July): 609648.

Borghans, Lex, and Bas ter Weel. 2006. "The Diffusion of Computers and the Distribution of Wages.” Unpublished paper, Maastricht University, October. Forthcoming in European Economic Review.

Bound, John, and George Johnson. 1992. "Changes in the Structure of Wages in the 1980s: An Evaluation of Alternative Explanations.” American Economic Review 82 (3, June): 371392.

Bresnahan, Timothy F. 1999. "Computerisation and Wage Dispersion: An Analytical Reinterpretation.” The Economic Journal 109 (June): F390-F415.

Buchinsky, Moshe. 1994. "Changes in the U.S. Wage Structure 1963-1987: Application of Quantile Regression.” Econometrica 62 (2, March): 405-458. 
Buchinsky, Moshe. 1998. "Recent Advances in Quantile Regression Models: A Practical Guideline for Empirical Research.” Journal of Human Resources 33 (Winter): 88-126.

Card, David, and John DiNardo. 2002. "Skill-Biased Technological Change and Rising Wage Inequality: Some Problems and Puzzles.” Journal of Labor Economics 20(4): 733-783.

Daly, Mary C., and Robert G. Valletta. 2004. "Inequality and Poverty in the United States: The Effects of Rising dispersion of Men's Earnings and Changing Family Behaviour. Economica 73 (Feb.): 75-98.

DiNardo, John, Nicole M. Fortin, and Thomas Lemieux. 1996. "Labour Market Institutions and the Distribution of Wages, 1973-1992: A Semiparametric Approach." Econometrica 64(5, September): 1001-1044.

DiNardo, John, and Jörn-Steffen Pischke. 1997. "The Return to Computer Use Revisited: Have Pencils Changed the Wage Structure Too?” Quarterly Journal of Economics 112 (1, Feb.): 291-303.

Feenstra, Robert C., and Gordon H. Hanson. 1999. "The Impact of Outsourcing and HighTechnology Capital on Wages: Estimates for the United States, 1979-1990.” Quarterly Journal of Economics 114 (3, Aug.): 907-40.

Katz, Lawrence, and Kevin M. Murphy. 1992. "Changes in Relative Wages, 1963-1987: Supply and Demand Factors.” Quarterly Journal of Economics 107 (1, Feb.): 35-78.

Koenker, Roger, and Gilbert Bassett, Jr. 1982. "Robust Tests for Heteroscedasticity Based on Regression Quantiles.” Econometrica 50(1): 43-61.

Krueger, Alan. 1993. "How Computers Have Changed the Wage Structure: Evidence from Microdata, 1984-1989.” Quarterly Journal of Economics 108 (1, Feb.): 33-60.

Krusell, Per, Lee E. Ohanian, Jose-Victor Rios-Rull, and Giovanni L. Violante. 2000. "CapitalSkill Complementarity and Inequality: A Macroeconomic Analysis.” Econometrica 68 (5, Sept.): 1029-1053.

Lee, David. 1999. "Wage Inequality in the United States during the 1980s: Rising Dispersion or Falling Minimum Wage?” Quarterly Journal of Economics 114 (Aug.): 977-1023.

Lemieux, Thomas. 2006. "Increasing Residual Wage Inequality: Composition Effects, Noisy Data, or Rising Demand for Skills?” American Economic Review 96 (3, June): 461-498.

Tashiro, Sanae. 2004. "The Diffusion of Computers and Wages in the U.S.: Occupation and Industry Analysis, 1984-2001.” Unpublished manuscript, Department of Economics, Rowan University. 
Weinberg, Bruce A. 2000. “Computer Use and the Demand for Female Workers.” Industrial and Labor Relations Review 53 (2, Jan.): 290-308.

Zoghi, Cindy, and Sabrina Wulff Pabilonia. 2005. “Who Gains from Computer Use?” Perspectives on Labour and Income 17(3): 27-34. 
Figure 1: Share of Workers who Directly Use a Computer at Work, by Education

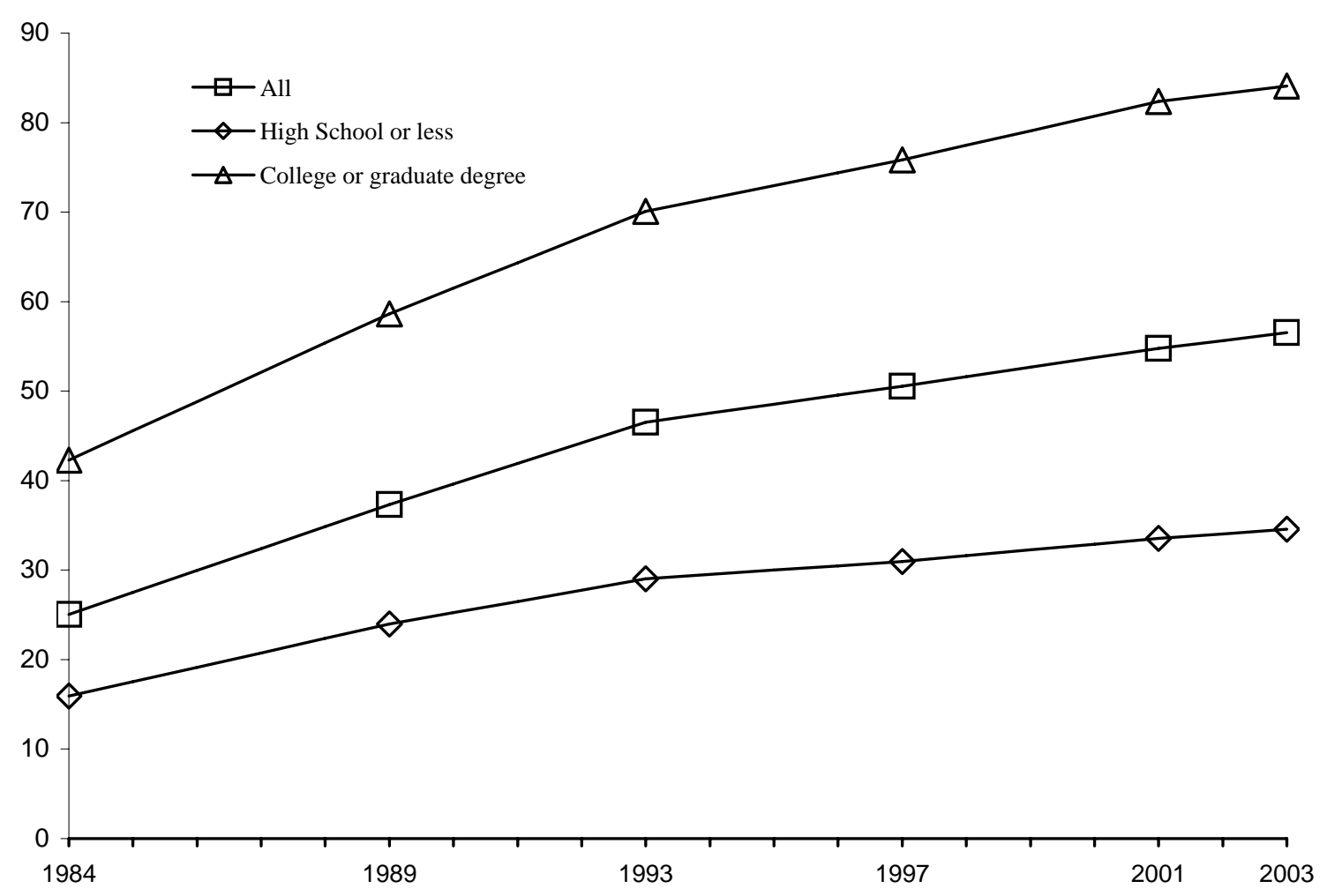

Note: Tabulated from the CPS computer use supplements. 
Figure 2: Wage Inequality, CPS-MORG and Computer Supplements

Panel A: All

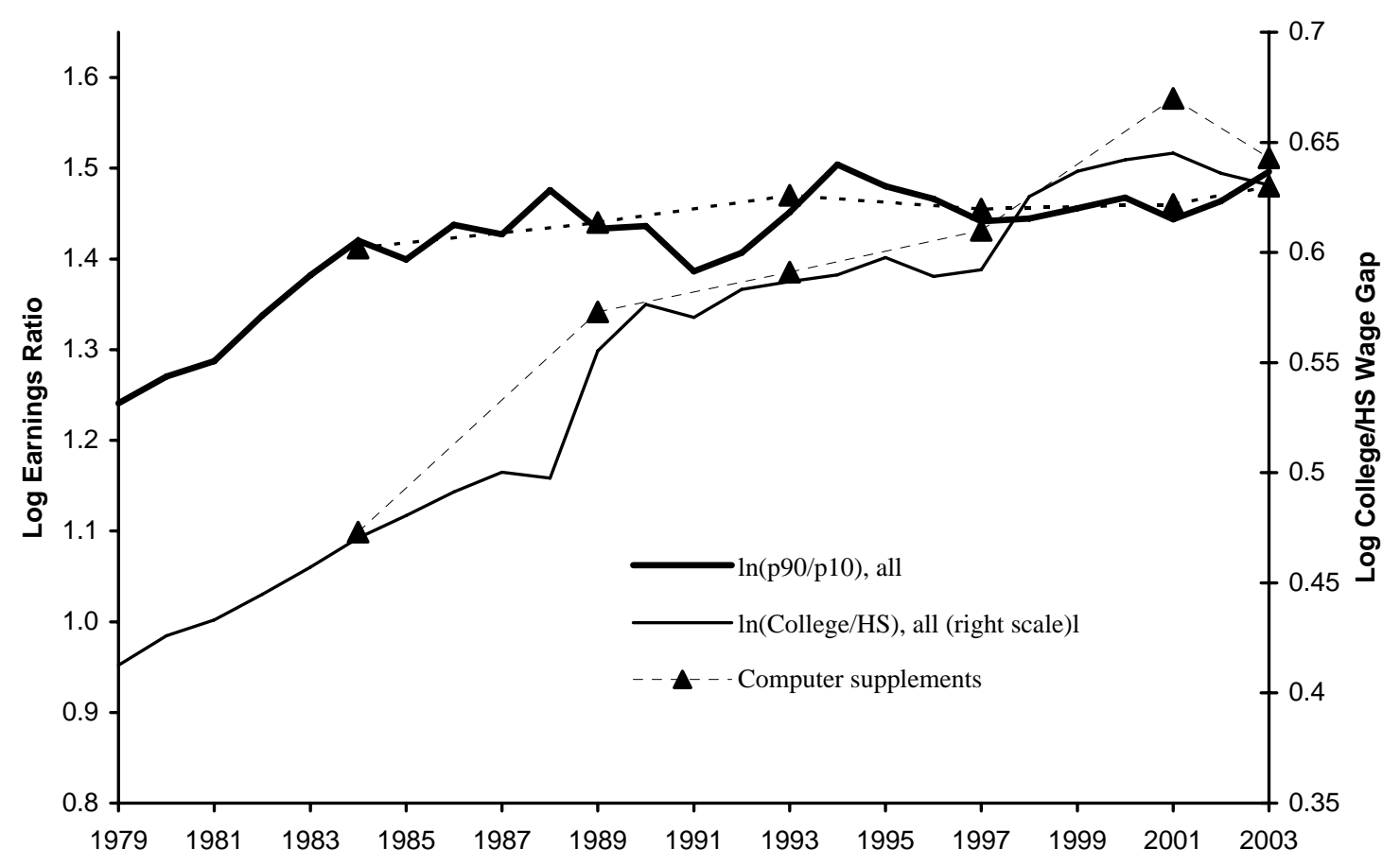

Panel B: Men and Women

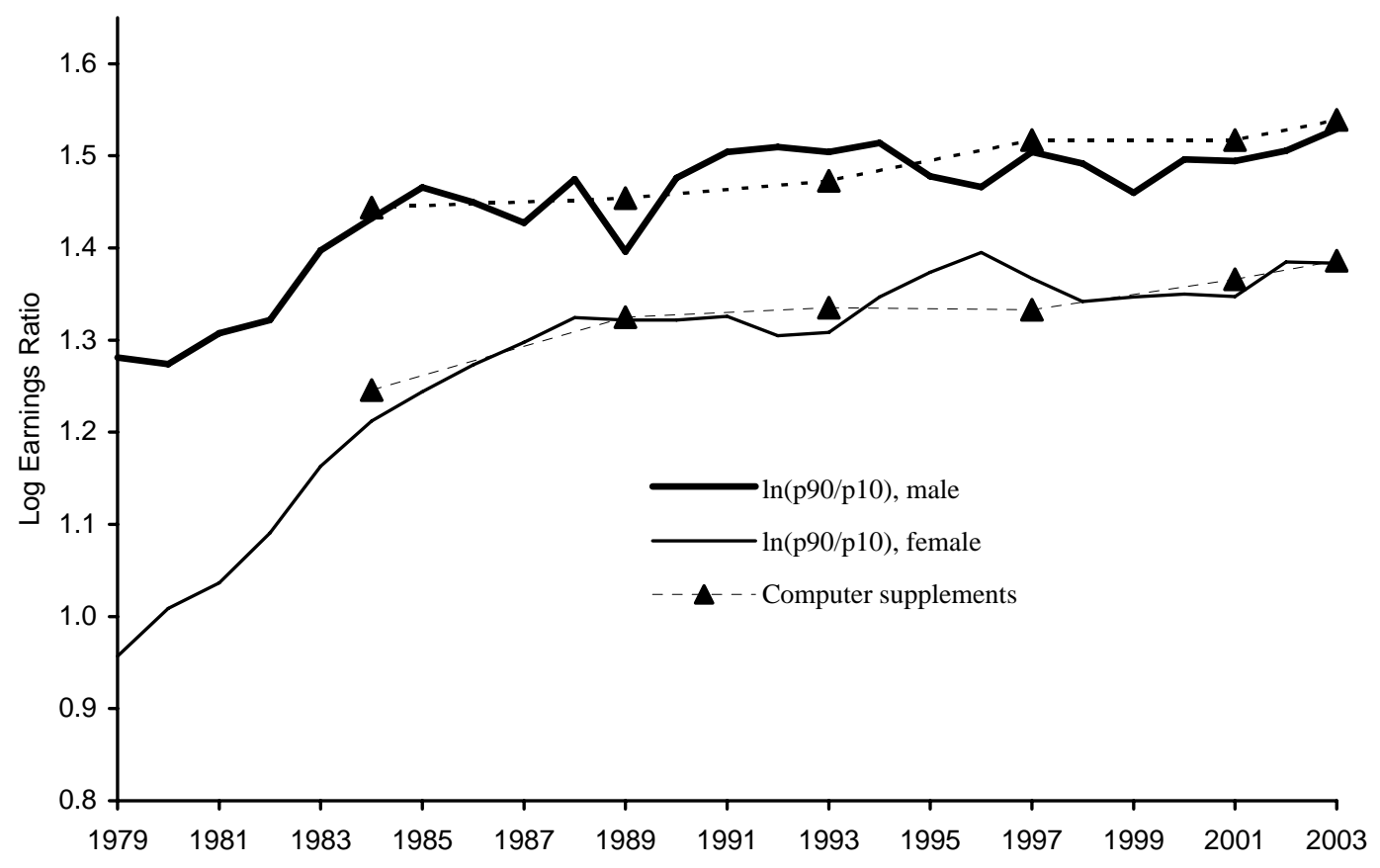

Note: Hourly wage data from the CPS monthly outgoing rotation groups (MORG) and computer use supplements. 
Figure 3: Wage Inequality, Upper and Lower Half, CPS-MORG

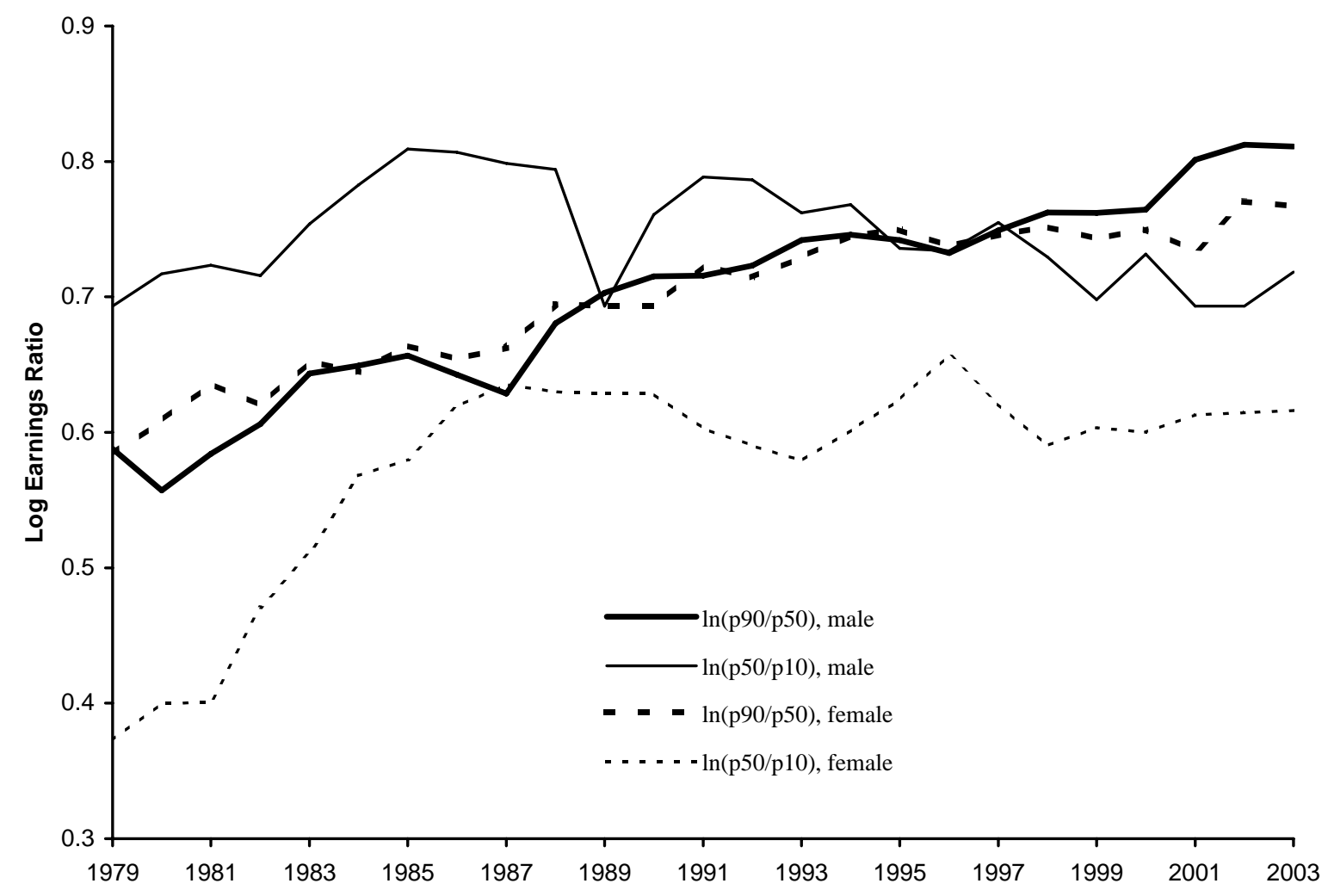

Note: Hourly wage data from the CPS monthly outgoing rotation groups (MORG). 
Figure 4. Percentage Return to Computer Use

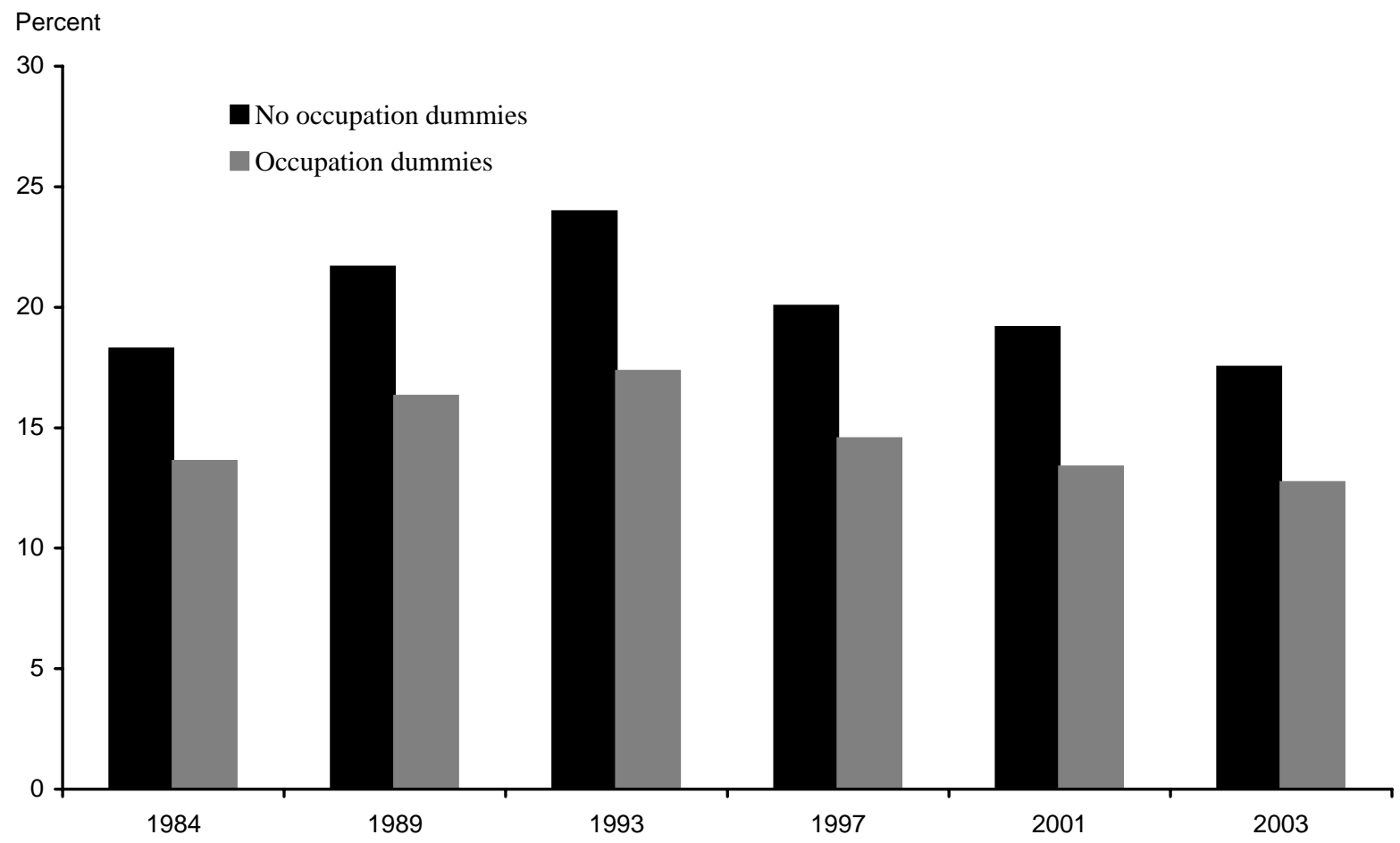

Note: Regression models include controls for education (4 categories), experience and its square, black, asian, other race, part-time worker, MSA status, veteran status, married, female, married * female interaction,union membership, 3 region dummies, and an intercept. 
Figure 5. Percentage Return to Computer Use by Education Level

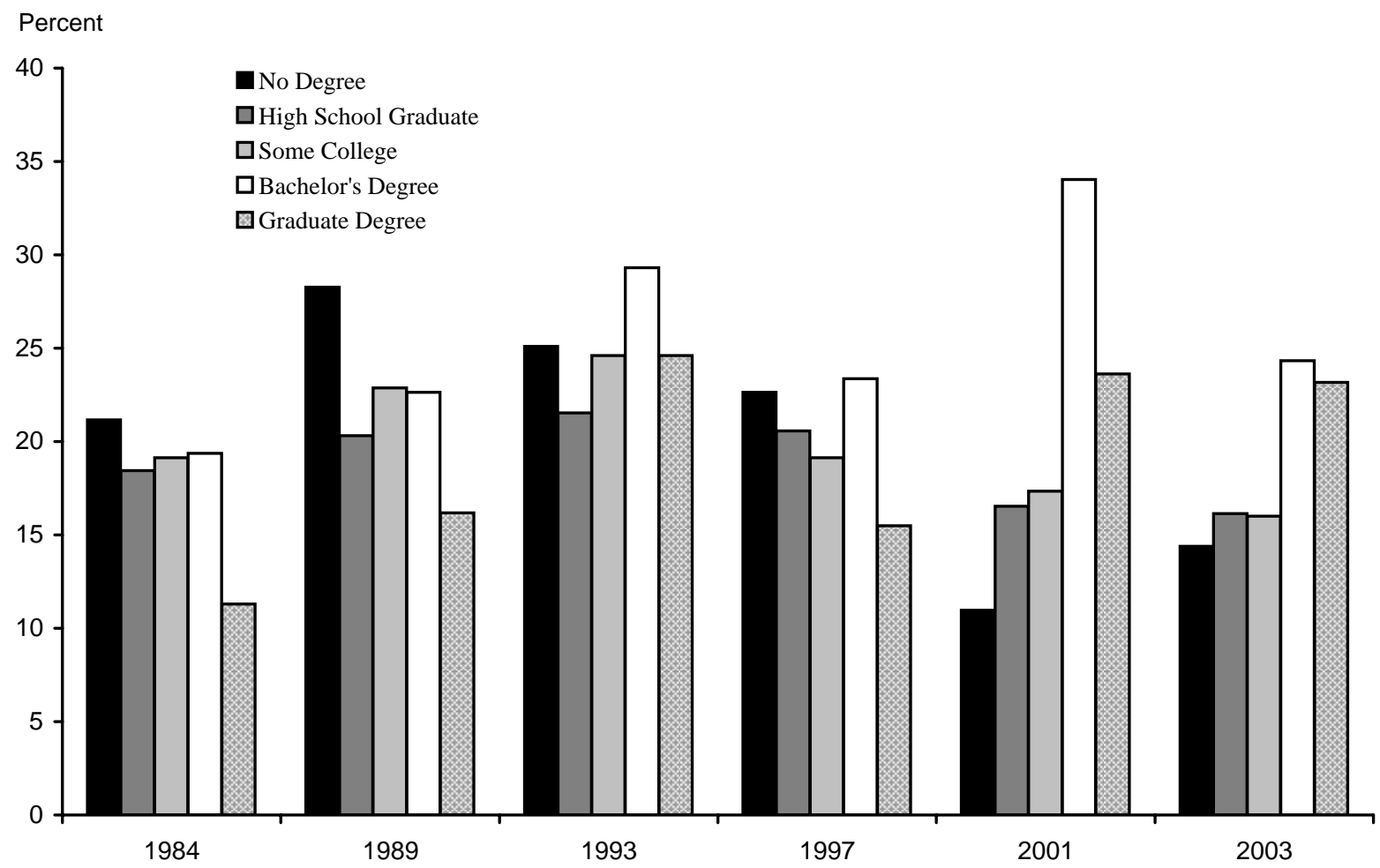

Note: Regression models include controls for experience and its square, black, asian, other race, part-time worker, MSA status, veteran status, married, female, married * female interaction, union membership, 3 region dummies, and an intercept. 


\section{Figure 6: Coefficients on Computer Use, by Wage Quantile,}

\section{Panel A: College Degree or More}

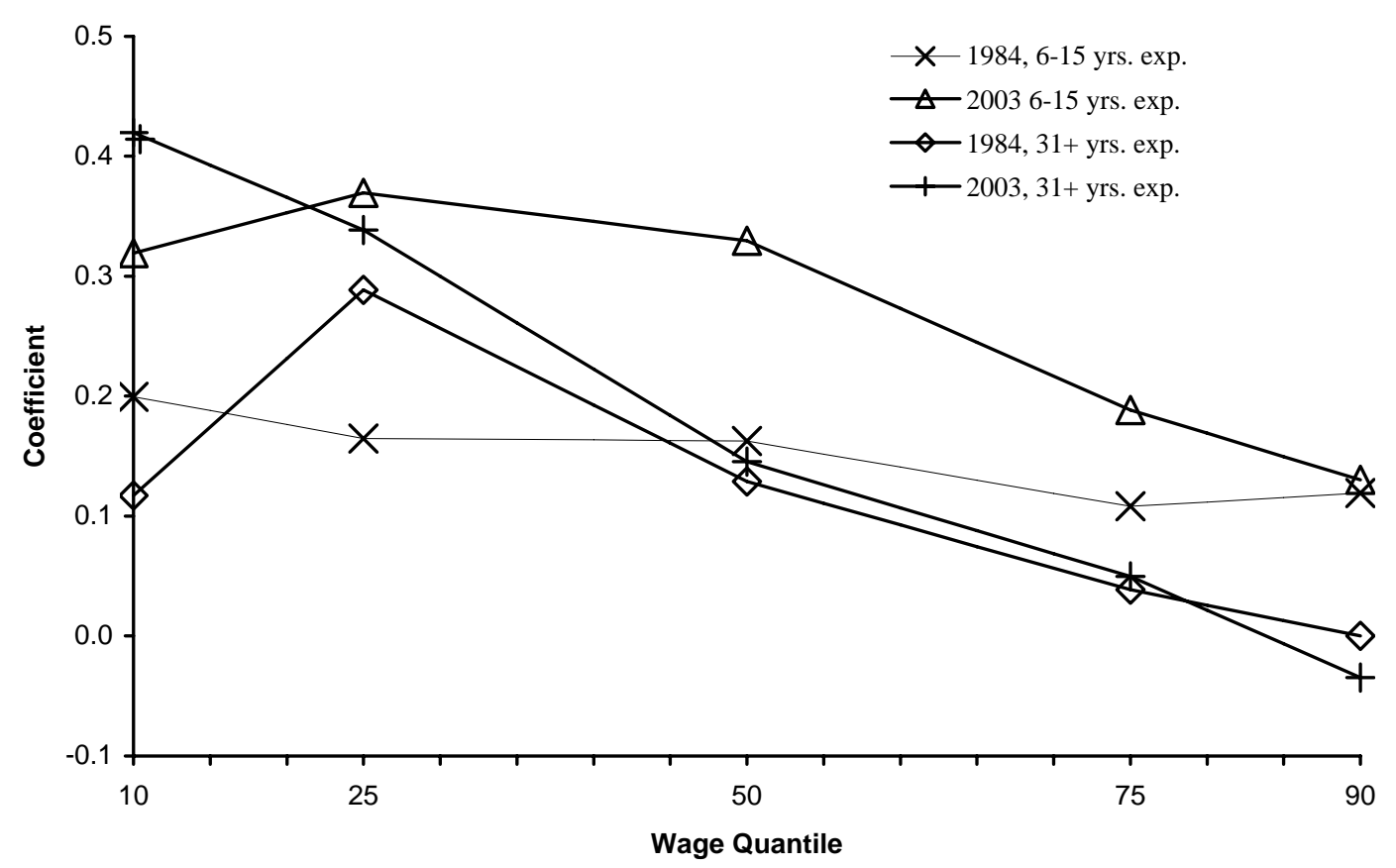

Panel B: High School Degree or Less

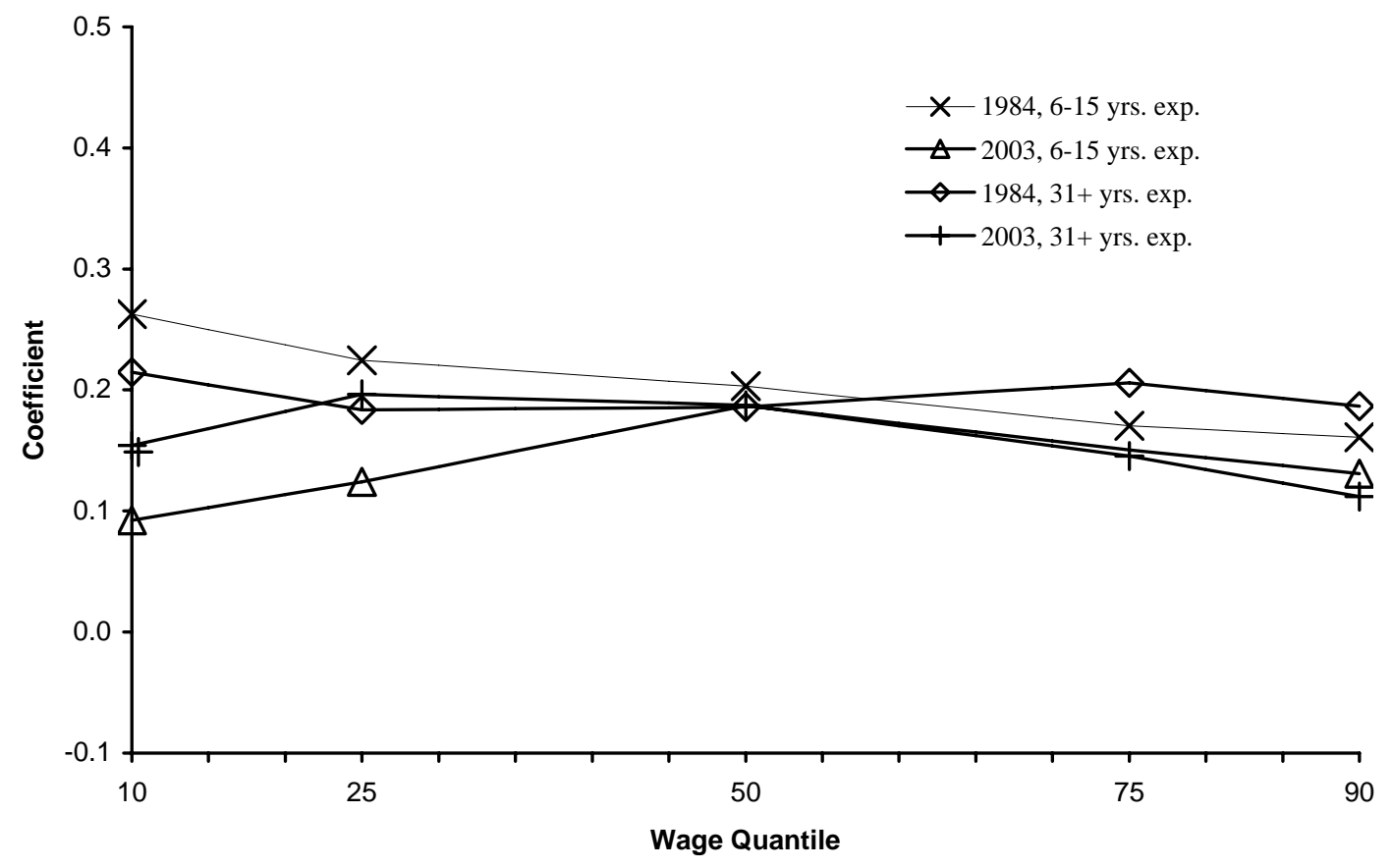

Note: Coefficient estimates from quantile regressions; other covariates same as Table 2. 
Figure 7. Impact of Computer Use on Wages, Men and Women

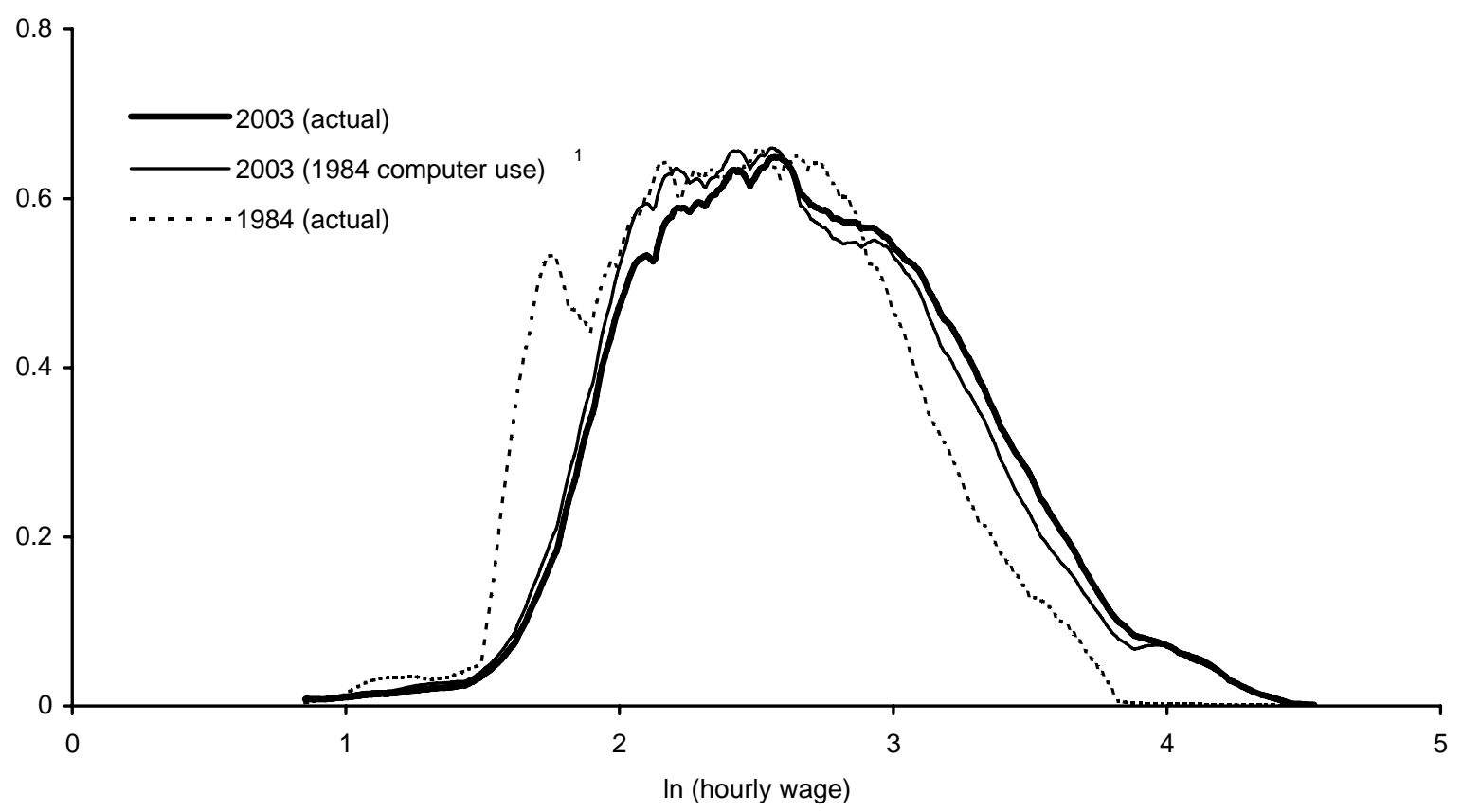

${ }^{1}$ Adjusted by relative probability of computer use in 1984, conditional on wage regression covariates. Note: See text for methodology. 
Table 1. Percentage of Workers Who Use a Computer at Work, by Selected Characteristics

\begin{tabular}{|c|c|c|c|c|c|c|}
\hline & $\underline{1984}$ & $\underline{1989}$ & $\underline{1993}$ & $\underline{1997}$ & 2001 & $\underline{2003}$ \\
\hline All Workers & 25.0 & 37.3 & 46.5 & 50.6 & 54.8 & 56.5 \\
\hline \multicolumn{7}{|l|}{ Sex } \\
\hline Men & 21.6 & 32.1 & 41.0 & 44.8 & 49.1 & 50.9 \\
\hline Women & 29.5 & 43.7 & 53.1 & 57.2 & 61.4 & 63.0 \\
\hline \multicolumn{7}{|l|}{ Education } \\
\hline Less than high schoo & 5.1 & 7.7 & 10.3 & 12.3 & 16.2 & 15.8 \\
\hline High school & 19.8 & 29.3 & 34.5 & 36.9 & 39.2 & 40.7 \\
\hline Some college & 31.4 & 45.9 & 53.0 & 56.2 & 58.1 & 58.3 \\
\hline College & 42.4 & 58.4 & 69.5 & 74.6 & 80.8 & 82.5 \\
\hline Post-college & 42.2 & 58.9 & 71.3 & 78.5 & 85.3 & 87.4 \\
\hline \multicolumn{7}{|l|}{$\underline{\text { Race }}$} \\
\hline White & 25.8 & 38.4 & 47.9 & 52.0 & 56.3 & 57.8 \\
\hline Black & 18.6 & 28.0 & 36.6 & 40.4 & 43.9 & 46.1 \\
\hline \multicolumn{7}{|l|}{ Age } \\
\hline Age 18-24 & 20.5 & 29.6 & 34.4 & 37.1 & 37.8 & 38.5 \\
\hline Age 25-39 & 29.5 & 41.4 & 49.8 & 53.1 & 57.8 & 58.4 \\
\hline Age 40-54 & 23.9 & 38.9 & 50.1 & 54.4 & 58.5 & 60.6 \\
\hline Age 55-65 & 17.3 & 26.6 & 36.8 & 44.2 & 52.9 & 57.2 \\
\hline \multicolumn{7}{|l|}{ Occupation } \\
\hline Blue-collar & 7.3 & 11.1 & 18.0 & 20.0 & 24.2 & 26.5 \\
\hline White-collar & 36.0 & 56.5 & 67.5 & 72.3 & 75.0 & 75.6 \\
\hline \multicolumn{7}{|l|}{ Union status } \\
\hline Union member & 19.8 & 31.7 & 39.1 & 44.8 & 48.4 & 54.4 \\
\hline Nonunion & 25.2 & 37.6 & 46.8 & 50.7 & 55.0 & 56.6 \\
\hline \multicolumn{7}{|l|}{ Hours } \\
\hline Part-time & 12.8 & 24.6 & 32.4 & 35.5 & 42.1 & 44.0 \\
\hline Full-time & 27.5 & 39.1 & 48.5 & 53.4 & 57.0 & 58.9 \\
\hline \multicolumn{7}{|l|}{ Region } \\
\hline Northeast & 25.4 & 37.4 & 46.8 & 50.5 & 54.8 & 57.3 \\
\hline Midwest & 24.2 & 36.4 & 46.6 & 50.8 & 55.8 & 57.5 \\
\hline South & 23.1 & 36.5 & 45.0 & 49.4 & 53.3 & 54.7 \\
\hline West & 28.8 & 39.6 & 48.7 & 52.3 & 56.0 & 57.7 \\
\hline Sample Size & 61965 & 63085 & 60156 & 56480 & 66811 & 64262 \\
\hline
\end{tabular}

Source: Author's tabulations of Computer and Internet Use Supplements to the U.S. Bureau of Labor Statistics' Current Population Survey (CPS). 
Table 2. OLS Cross-Section Estimates of the Relationship Between Computer Use and Wages (Dependent variable: Log Hourly Wages)

\begin{tabular}{|c|c|c|c|c|c|c|c|c|c|c|c|c|c|c|c|c|c|c|}
\hline & \multicolumn{3}{|c|}{$\begin{array}{c}1984 \\
\mathrm{~N}=13401\end{array}$} & \multicolumn{3}{|c|}{$\begin{array}{c}1989 \\
\mathrm{~N}=13421\end{array}$} & \multicolumn{3}{|c|}{$\begin{array}{c}1993 \\
N=13398\end{array}$} & \multicolumn{3}{|c|}{$\begin{array}{c}1997 \\
\mathrm{~N}=12175\end{array}$} & \multicolumn{3}{|c|}{$\begin{array}{c}2001 \\
N=14308\end{array}$} & \multicolumn{3}{|c|}{$\begin{array}{c}2003 \\
\mathrm{~N}=13980\end{array}$} \\
\hline & (i) & (ii) & (iii) & (i) & (ii) & (iii) & (i) & (ii) & (iii) & (i) & (ii) & (iii) & (i) & (ii) & (iii) & (i) & (ii) & (iii) \\
\hline Computer Use & & $\begin{array}{l}0.164^{* *} \\
(.008)\end{array}$ & $\begin{array}{l}0.192^{* *} \\
(.040)\end{array}$ & & $\begin{array}{l}0.192 * * \\
(.008)\end{array}$ & $\begin{array}{l}0.249 * * \\
(.038)\end{array}$ & & $\begin{array}{l}0.217^{* *} \\
(.008)\end{array}$ & $\begin{array}{l}0.224^{* *} \\
(.038)\end{array}$ & & $\begin{array}{l}0.184^{* *} \\
(.009)\end{array}$ & $\begin{array}{l}0.204^{* *} \\
(.040)\end{array}$ & & $\begin{array}{l}0.175^{* *} \\
(.009)\end{array}$ & $\begin{array}{l}0.104^{* *} \\
(.034)\end{array}$ & & $\begin{array}{l}0.161 * * \\
(.009)\end{array}$ & $\begin{array}{l}0.134^{* *} \\
(.034)\end{array}$ \\
\hline High School Grad & $\begin{array}{l}0.162 * * \\
(.012)\end{array}$ & $\begin{array}{l}0.145^{* *} \\
(.011)\end{array}$ & $\begin{array}{l}0.146 * * \\
(.012)\end{array}$ & $\begin{array}{l}0.190^{* *} \\
(.012)\end{array}$ & $\begin{array}{l}0.154^{* *} \\
(.012)\end{array}$ & $\begin{array}{l}0.161^{* *} \\
(.013)\end{array}$ & $\begin{array}{l}0.191 * * \\
(.014)\end{array}$ & $\begin{array}{l}0.144 * * \\
(.014)\end{array}$ & $\begin{array}{l}0.152^{* *} \\
(.015)\end{array}$ & $\begin{array}{l}0.198^{* *} \\
(.015)\end{array}$ & $\begin{array}{l}0.160^{* *} \\
(.015)\end{array}$ & $\begin{array}{l}0.162^{* *} \\
(.016)\end{array}$ & $\begin{array}{l}0.212^{* *} \\
(.015)\end{array}$ & $\begin{array}{l}0.181^{* *} \\
(.014)\end{array}$ & $\begin{array}{l}0.177^{* *} \\
(.016)\end{array}$ & $\begin{array}{l}0.238^{* *} \\
(.016)\end{array}$ & $\begin{array}{l}0.210^{* *} \\
(.016)\end{array}$ & $\begin{array}{l}0.210^{* *} \\
(.018)\end{array}$ \\
\hline Some College & $\begin{array}{l}0.297^{* *} \\
(.013)\end{array}$ & $\begin{array}{l}0.263^{* *} \\
(.013)\end{array}$ & $\begin{array}{l}0.261 * * \\
(.014)\end{array}$ & $\begin{array}{l}0.366^{* *} \\
(.014)\end{array}$ & $\begin{array}{l}0.296^{* *} \\
(.014)\end{array}$ & $\begin{array}{l}0.294^{* *} \\
(.015)\end{array}$ & $\begin{array}{l}0.339 * * \\
(.015)\end{array}$ & $\begin{array}{l}0.242^{* *} \\
(.015)\end{array}$ & $\begin{array}{l}0.251^{* *} \\
(.016)\end{array}$ & $\begin{array}{l}0.338^{* *} \\
(.015)\end{array}$ & $\begin{array}{l}0.263^{* *} \\
(.016)\end{array}$ & $\begin{array}{l}0.272^{* *} \\
(.018)\end{array}$ & $\begin{array}{l}0.344^{* *} \\
(.015)\end{array}$ & $\begin{array}{l}0.280^{* *} \\
(.015)\end{array}$ & $\begin{array}{l}0.276 * * \\
(.018)\end{array}$ & $\begin{array}{l}0.371^{* *} \\
(.016)\end{array}$ & $\begin{array}{l}0.315^{* *} \\
(.016)\end{array}$ & $\begin{array}{l}0.318^{* *} \\
(.019)\end{array}$ \\
\hline Bachelor's Degree & $\begin{array}{l}0.504^{* *} \\
(.014)\end{array}$ & $\begin{array}{l}0.455^{* *} \\
(.014)\end{array}$ & $\begin{array}{l}0.451 * * \\
(.017)\end{array}$ & $\begin{array}{l}0.611^{* *} \\
(.015)\end{array}$ & $\begin{array}{l}0.521^{* *} \\
(.015)\end{array}$ & $\begin{array}{l}0.520^{* *} \\
(.019)\end{array}$ & $\begin{array}{l}0.641^{* *} \\
(.016)\end{array}$ & $\begin{array}{l}0.518^{* *} \\
(.016)\end{array}$ & $\begin{array}{l}0.490^{* *} \\
(.021)\end{array}$ & $\begin{array}{l}0.639 * * \\
(.017)\end{array}$ & $\begin{array}{l}0.537^{* *} \\
(.017)\end{array}$ & $\begin{array}{l}0.520^{* *} \\
(.023)\end{array}$ & $\begin{array}{l}0.655^{* *} \\
(.016)\end{array}$ & $\begin{array}{l}0.554^{* *} \\
(.017)\end{array}$ & $\begin{array}{l}0.446 * * \\
(.025)\end{array}$ & $\begin{array}{l}0.680^{* *} \\
(.017)\end{array}$ & $\begin{array}{l}0.589 * * \\
(.018)\end{array}$ & $\begin{array}{l}0.537^{* *} \\
(.026)\end{array}$ \\
\hline Graduate Degree & $\begin{array}{l}0.612^{* *} \\
(.016)\end{array}$ & $\begin{array}{l}0.557^{* *} \\
(.016)\end{array}$ & $\begin{array}{l}0.585^{* *} \\
(.019)\end{array}$ & $\begin{array}{l}0.733^{* *} \\
(.016)\end{array}$ & $\begin{array}{l}0.638^{* *} \\
(.016)\end{array}$ & $\begin{array}{l}0.670^{* *} \\
(.022)\end{array}$ & $\begin{array}{l}0.793^{* *} \\
(.018)\end{array}$ & $\begin{array}{l}0.664^{* *} \\
(.019)\end{array}$ & $\begin{array}{l}0.662 * * \\
(.029)\end{array}$ & $\begin{array}{l}0.782 \text { ** } \\
(.020)\end{array}$ & $\begin{array}{l}0.671^{* *} \\
(.020)\end{array}$ & $\begin{array}{l}0.706^{* *} \\
(.033)\end{array}$ & $\begin{array}{l}0.823^{* *} \\
(.019)\end{array}$ & $\begin{array}{l}0.710^{* *} \\
(.019)\end{array}$ & $\begin{array}{l}0.665^{* *} \\
(.040)\end{array}$ & $\begin{array}{l}0.830^{* *} \\
(.019)\end{array}$ & $\begin{array}{l}0.732 * * \\
(.020)\end{array}$ & $\begin{array}{l}0.685 * * \\
(.039)\end{array}$ \\
\hline \multicolumn{2}{|c|}{ Comp. Use * HS Grad } & & $\begin{array}{l}-0.023 \\
(.042)\end{array}$ & & & $\begin{array}{l}-0.064 \\
(.040)\end{array}$ & & & $\begin{array}{l}-0.029 \\
(.040)\end{array}$ & & & $\begin{array}{l}-0.017 \\
(.041)\end{array}$ & & & $\begin{array}{l}0.049 \\
(.036)\end{array}$ & & & $\begin{array}{l}0.015 \\
(.037)\end{array}$ \\
\hline \multicolumn{3}{|c|}{ Comp. Use * Some College } & $\begin{array}{l}-0.017 \\
(.043)\end{array}$ & & & $\begin{array}{l}-0.043 \\
(.040)\end{array}$ & & & $\begin{array}{l}-0.004 \\
(.040)\end{array}$ & & & $\begin{array}{l}-0.029 \\
(.042)\end{array}$ & & & $\begin{array}{l}0.056 \\
(.036)\end{array}$ & & & $\begin{array}{l}0.014 \\
(.037)\end{array}$ \\
\hline \multicolumn{3}{|c|}{ Comp. Use * Bachelor's } & $\begin{array}{l}-0.015 \\
(.044)\end{array}$ & & & $\begin{array}{l}-0.045 \\
(.042)\end{array}$ & & & $\begin{array}{l}0.033 \\
(.043)\end{array}$ & & & $\begin{array}{l}0.006 \\
(.044)\end{array}$ & & & $\begin{array}{l}0.189 * * \\
(.040)\end{array}$ & & & $\begin{array}{l}0.083^{*} \\
(.041)\end{array}$ \\
\hline Comp. Use * Grad & & & $\begin{array}{l}-0.085 \\
(.045)\end{array}$ & & & $\begin{array}{l}-0.099 \\
(.044)\end{array}$ & & & $\begin{array}{l}-0.004 \\
(.048)\end{array}$ & & & $\begin{array}{l}-0.060 \\
(.051)\end{array}$ & & & $\begin{array}{l}0.108^{*} \\
(.052)\end{array}$ & & & $\begin{array}{l}0.074 \\
(.052)\end{array}$ \\
\hline Adjusted R-Square & 0.429 & 0.445 & 0.445 & 0.423 & 0.447 & 0.447 & 0.391 & 0.422 & 0.422 & 0.401 & 0.423 & 0.423 & 0.361 & 0.379 & 0.381 & 0.354 & 0.369 & 0.369 \\
\hline
\end{tabular}

Note: Data from the Computer and Internet Use Supplements to the U.S. Bureau of Labor Statistics' Current Population Survey (CPS).

Models include controls for experience and its square, black, asian, other race, part-time worker, MSA status, veteran status, married, female, married * female interaction, union membership,

3 region dummies, and an intercept.

\section{* -- significant at the $5 \%$ level}

** -- significant at the $1 \%$ level 
Table 3. Computer Effect on Wages, Quantile Regressions (Full Sample)

\begin{tabular}{c|cccccc} 
year & \multicolumn{7}{|c}{ Quantile } & $\underline{\text { mean }}$ \\
\hline & $\underline{0.10}$ & $\underline{0.25}$ & $\underline{0.50}$ & $\underline{0.75}$ & $\underline{0.90}$ & $\underline{(\text { OLS }}$ \\
1984 & 0.180 & 0.179 & 0.166 & 0.155 & 0.139 & 0.164 \\
1989 & 0.223 & 0.214 & 0.197 & 0.175 & 0.151 & 0.192 \\
1993 & 0.229 & 0.223 & 0.219 & 0.205 & 0.172 & 0.217 \\
1997 & 0.184 & 0.187 & 0.192 & 0.186 & 0.129 & 0.184 \\
2001 & 0.186 & 0.175 & 0.176 & 0.160 & 0.132 & 0.175 \\
2003 & 0.164 & 0.169 & 0.173 & 0.149 & 0.110 & 0.161
\end{tabular}

Note: All listed coefficients significant at the $1 \%$ level. Sample size and other control variables same as in Table 2. 
Table 4: Contribution of Computer Use to Changes in the Distribution of Earnings per Hour, 1984 to 2003 (ALL WORKERS)

(1) (2)

All Education

\begin{tabular}{l|} 
Statistic \\
Median $^{1}$ \\
Standard Deviation \\
$\ln (\mathrm{p} 90 / \mathrm{p} 10)^{2}$ \\
$\ln (\mathrm{p} 90 / \mathrm{p} 50)$ \\
$\ln (\mathrm{p} 50 / \mathrm{p} 10)$ \\
$\ln (\mathrm{p} 75 / \mathrm{p} 25)$ \\
$\ln (\mathrm{p} 95 / \mathrm{p} 5)$ \\
Gini Coefficient \\
Theil Index \\
Mean Log Deviation \\
College/HS Gap
\end{tabular}

\begin{tabular}{cc}
\hline Total Change & Computer Use \\
\cline { 1 - 2 } 0.152 & 0.064 \\
& {$[0.425]$} \\
0.050 & -0.002 \\
& {$[-0.032]$} \\
0.068 & 0.025 \\
& {$[0.368]$} \\
0.094 & -0.024 \\
& {$[-0.250]$} \\
-0.026 & 0.049 \\
& {$[-1.846]$} \\
0.042 & -0.005 \\
& {$[-0.110]$} \\
0.119 & -0.040 \\
& {$[-0.340]$} \\
0.030 & -0.003 \\
& {$[-0.109]$} \\
0.037 & -0.006 \\
& {$[-0.175]$} \\
0.032 & -0.003 \\
& {$[-0.107]$} \\
0.170 & 0.047 \\
& {$[0.276]$}
\end{tabular}

(3)

(4)

Bachelor's or more Total Change Computer Use

0.245

0.068

0.100

0.100

0.039

0.061

0.100

[0.410]

$-0.047$

[-0.697]

$-0.104$

[-1.038]

$-0.060$

[-1.523]

$-0.044$

[-0.726]

$-0.062$

[-0.676]

$-0.192$

[-0.815]

$-0.024$

[-0.649]

$-0.025$

[-0.699]

$-0.027$

[-0.736]
(5) Total Change Computer Use 0.099

0.032

[0.318]

0.000

[-0.311]

0.003

$[-0.056]$

$-0.003$

[-7.973]

0.006

[-0.112]

0.026

[-2.179]

$-0.026$

[1.651]

$-0.002$

[-10.861]

$-0.004$

[-0.605]

$-0.002$

[-0.715]

Note: Numbers in brackets indicate the share of the explained change in the total change. Earnings expressed in 2003 dollars. Estimated from the 1984 and 2003 CPS computer use supplements. Figures in columns (2), (4) and (6) indicate the impact of rising computer use, conditional on the wage equation covariates from Table 2 (columns (i)).

${ }^{1}$ The median, standard deviation, and percentile gaps are calculated from the distribution of $\log ($ earnings/hour); the other statistics are calculated from the unlogged data.

${ }^{2}$ Difference between the 90th and 10th percentile of the log wage distribution; other gaps defined similarly. 
Table 5: Contribution of Computer Use to Changes in the Distribution of Earnings per Hour, 1984 to 2003 (MEN)

(1) (2) (3) (4) (6) (6)

\begin{tabular}{|c|c|c|c|c|c|c|}
\hline \multirow[b]{2}{*}{ Statistic } & \multicolumn{2}{|c|}{$\begin{array}{c}\text { All Education } \\
\end{array}$} & \multicolumn{2}{|c|}{ Bachelor's or more } & \multicolumn{2}{|c|}{ High School or Less } \\
\hline & Total Change & Computer Use & Total Change & Computer Use & Total Change & Computer Use \\
\hline $\operatorname{Median}^{1}$ & 0.079 & $\begin{array}{c}0.066 \\
{[0.839]}\end{array}$ & 0.226 & $\begin{array}{c}0.148 \\
{[0.653]}\end{array}$ & -0.010 & $\begin{array}{c}0.041 \\
{[-4.099]}\end{array}$ \\
\hline Standard Deviation & 0.068 & $\begin{array}{c}0.004 \\
{[0.053]}\end{array}$ & 0.074 & $\begin{array}{c}-0.050 \\
{[-0.675]}\end{array}$ & 0.009 & $\begin{array}{c}0.001 \\
{[0.063]}\end{array}$ \\
\hline $\ln (\mathrm{p} 90 / \mathrm{p} 10)^{2}$ & 0.096 & $\begin{array}{c}0.061 \\
{[0.638]}\end{array}$ & 0.222 & $\begin{array}{c}-0.154 \\
{[-0.694]}\end{array}$ & -0.020 & $\begin{array}{c}0.006 \\
{[-0.329]}\end{array}$ \\
\hline $\ln (\mathrm{p} 90 / \mathrm{p} 50)$ & 0.155 & $\begin{array}{c}-0.005 \\
{[-0.033]}\end{array}$ & 0.068 & $\begin{array}{c}-0.148 \\
{[-2.178]}\end{array}$ & 0.061 & $\begin{array}{c}-0.034 \\
{[-0.563]}\end{array}$ \\
\hline $\ln (\mathrm{p} 50 / \mathrm{p} 10)$ & -0.059 & $\begin{array}{c}0.066 \\
{[-1.122]}\end{array}$ & 0.154 & $\begin{array}{c}-0.007 \\
{[-0.042]}\end{array}$ & -0.081 & $\begin{array}{c}0.041 \\
{[-0.506]}\end{array}$ \\
\hline $\ln (\mathrm{p} 75 / \mathrm{p} 25)$ & 0.143 & $\begin{array}{c}0.066 \\
{[0.462]}\end{array}$ & 0.167 & $\begin{array}{c}-0.115 \\
{[-0.690]}\end{array}$ & -0.011 & $\begin{array}{c}0.014 \\
{[-1.295]}\end{array}$ \\
\hline $\ln (\mathrm{p} 95 / \mathrm{p} 5)$ & 0.130 & $\begin{array}{c}0.001 \\
{[0.004]}\end{array}$ & 0.187 & $\begin{array}{c}-0.212 \\
{[-1.133]}\end{array}$ & -0.031 & $\begin{array}{l}-0.017 \\
{[0.557]}\end{array}$ \\
\hline Gini Coefficient & 0.045 & $\begin{array}{c}-0.003 \\
{[-0.065]}\end{array}$ & 0.043 & $\begin{array}{c}-0.035 \\
{[-0.816]}\end{array}$ & 0.008 & $\begin{array}{c}-0.001 \\
{[-0.098]}\end{array}$ \\
\hline Theil Index & 0.050 & $\begin{array}{c}-0.007 \\
{[-0.131]}\end{array}$ & 0.039 & $\begin{array}{c}-0.035 \\
{[-0.879]}\end{array}$ & 0.011 & $\begin{array}{c}-0.002 \\
{[-0.174]}\end{array}$ \\
\hline Mean Log Deviation & 0.044 & $\begin{array}{c}-0.002 \\
{[-0.046]}\end{array}$ & 0.040 & $\begin{array}{c}-0.033 \\
{[-0.837]}\end{array}$ & 0.007 & $\begin{array}{c}-0.001 \\
{[-0.098]}\end{array}$ \\
\hline College/HS Gap & 0.251 & $\begin{array}{c}0.059 \\
{[0.234]}\end{array}$ & -- & -- & -- & -- \\
\hline
\end{tabular}

Note: Numbers in brackets indicate the share of the explained change in the total change. Earnings expressed in 2003 dollars. Estimated from the 1984 and 2003 CPS computer use supplements. Figures in columns (2), (4) and (6) indicate the impact of rising computer use, conditional on the wage equation covariates from Table 2 (columns (i)).

${ }^{1}$ The median, standard deviation, and percentile gaps are calculated from the distribution of log(earnings/hour); the other statistics are calculated from the unlogged data.

${ }^{2}$ Difference between the 90th and 10th percentile of the log wage distribution; other gaps defined similarly. 
Table 6: Contribution of Computer Use to Changes in the Distribution of Earnings per Hour, 1984 to 2003 (WOMEN)
(1)
(2)
(3)
(4)
(5)
(6)

\begin{tabular}{|c|c|c|c|c|c|c|}
\hline \multirow[b]{2}{*}{ Statistic } & \multicolumn{2}{|c|}{ All Education } & \multicolumn{2}{|c|}{ Bachelor's or more } & \multicolumn{2}{|c|}{ High School or Less } \\
\hline & Total Change & Computer Use & Total Change & Computer Use & Total Change & Computer Use \\
\hline Median $^{1}$ & 0.273 & $\begin{array}{c}0.068 \\
{[0.251]}\end{array}$ & 0.258 & $\begin{array}{c}0.041 \\
{[0.159]}\end{array}$ & 0.185 & $\begin{array}{c}0.041 \\
{[0.221]}\end{array}$ \\
\hline Standard Deviation & 0.073 & $\begin{array}{c}-0.012 \\
{[-0.170]}\end{array}$ & 0.080 & $\begin{array}{c}-0.061 \\
{[-0.759]}\end{array}$ & 0.042 & $\begin{array}{c}0.002 \\
{[0.036]}\end{array}$ \\
\hline $\ln (\mathrm{p} 90 / \mathrm{p} 10)^{2}$ & 0.140 & $\begin{array}{c}-0.016 \\
{[-0.111]}\end{array}$ & 0.232 & $\begin{array}{c}-0.146 \\
{[-0.631]}\end{array}$ & 0.072 & $\begin{array}{c}-0.029 \\
{[-0.398]}\end{array}$ \\
\hline $\ln (\mathrm{p} 90 / \mathrm{p} 50)$ & 0.105 & $\begin{array}{c}-0.045 \\
{[-0.427]}\end{array}$ & 0.133 & $\begin{array}{c}-0.041 \\
{[-0.307]}\end{array}$ & 0.022 & $\begin{array}{c}-0.029 \\
{[-1.309]}\end{array}$ \\
\hline $\ln (\mathrm{p} 50 / \mathrm{p} 10)$ & 0.035 & $\begin{array}{c}0.029 \\
{[0.848]}\end{array}$ & 0.099 & $\begin{array}{c}-0.106 \\
{[-1.064]}\end{array}$ & 0.050 & $\begin{array}{c}0.000 \\
{[0.000]}\end{array}$ \\
\hline $\ln (\mathrm{p} 75 / \mathrm{p} 25)$ & 0.067 & $\begin{array}{c}-0.017 \\
{[-0.261]}\end{array}$ & 0.092 & $\begin{array}{c}-0.055 \\
{[-0.603]}\end{array}$ & 0.040 & $\begin{array}{c}0.064 \\
{[1.615]}\end{array}$ \\
\hline $\ln (\mathrm{p} 95 / \mathrm{p} 5)$ & 0.317 & $\begin{array}{c}0.000 \\
{[-0.002]}\end{array}$ & 0.240 & $\begin{array}{c}-0.137 \\
{[-0.571]}\end{array}$ & 0.185 & $\begin{array}{c}-0.003 \\
{[-0.015]}\end{array}$ \\
\hline Gini Coefficient & 0.039 & $\begin{array}{c}-0.009 \\
{[-0.237]}\end{array}$ & 0.039 & $\begin{array}{c}-0.022 \\
{[-0.577]}\end{array}$ & 0.023 & $\begin{array}{c}-0.002 \\
{[-0.065]}\end{array}$ \\
\hline Theil Index & 0.041 & $\begin{array}{c}-0.013 \\
{[-0.312]}\end{array}$ & 0.034 & $\begin{array}{c}-0.022 \\
{[-0.646]}\end{array}$ & 0.030 & $\begin{array}{c}-0.008 \\
{[-0.269]}\end{array}$ \\
\hline Mean Log Deviation & 0.039 & $\begin{array}{c}-0.010 \\
{[-0.246]}\end{array}$ & 0.037 & $\begin{array}{c}-0.028 \\
{[-0.749]}\end{array}$ & 0.023 & $\begin{array}{c}-0.002 \\
{[-0.110]}\end{array}$ \\
\hline College/HS Gap & 0.108 & $\begin{array}{c}-0.003 \\
{[-0.032]}\end{array}$ & -- & -- & -- & -- \\
\hline
\end{tabular}

Note: Numbers in brackets indicate the share of the explained change in the total change. Earnings expressed in 2003 dollars. Estimated from the 1984 and 2003 CPS computer use supplements. Figures in columns (2), (4) and (6) indicate the impact of rising computer use, conditional on the wage equation covariates from Table 2 (columns (i)).

${ }^{1}$ The median, standard deviation, and percentile gaps are calculated from the distribution of log(earnings/hour); the other statistics are calculated from the unlogged data.

${ }^{2}$ Difference between the 90th and 10th percentile of the log wage distribution; other gaps defined similarly. 


\section{Appendix A: Conditional Density Estimation}

This appendix describes the conditional density estimation technique used to obtain the results presented in Figure 7 and Tables 4-6 in the main text. This discussion largely follows that in DiNardo, Fortin, and Lemieux (1996; DFL), although they provide a more complete and therefore more complex decomposition of changing earnings inequality (see also Lemieux 2006 for an alternative application).

Consider the distribution of wages $w$ in year $t$, conditional on individual attributes $X$ and a dummy variable $(C)$ indicating computer use on the job:

$$
f_{t}(w) \equiv f\left(w ; t_{w}=t, t_{C \mid X}=t, t_{X}=t\right)
$$

This identity is notational; it shows that the distribution of $w$ is defined in year $t$, conditional on the distribution of $C$ (conditional on $X$ ) and $X$ in the same year. In the text, I focus on $t_{w}=2003$. The vector $X$ includes the complete set of covariates (other than computer use) from the wage regressions in the text.

The essence of the test is to investigate the effect of holding $t_{C \mid X}$ at earlier year (1984) levels-i.e., to estimate what the distribution of earnings would be in 2003 if the level and conditional pattern of workplace computer use had remained the same as in 1984. Thus, we need to estimate the 2003 distribution of earnings with the pattern of computer use and its relationship to $X$ held to that observed in 1984 .

We proceed as follows. A distribution such as (A1) can be expressed as:

$$
f_{t}(w)=\iint f\left(w \mid C, X, t_{w}=t\right) d F\left(C \mid X, t_{C \mid X}=t\right) d F\left(X \mid t_{X}=t\right)
$$

In this equation, $f_{t}(w)$ is the density of $w$ at time $t$, which can be expressed as the conditional density integrated over the distribution of computer use (conditional on individual attributes) and individual attributes. 
We are interested (for example) in the 2003 distribution of $w$ if the distribution of $C$ conditional on $X$ is held to its 1984 structure:

$$
f\left(w ; t_{w}=03, t_{C \mid X}=84, t_{X}=03\right)
$$

Using (A2), this distribution can be expressed as:

$$
\begin{aligned}
f_{t}\left(w ; t_{w}=\right. & \left.03, t_{C \mid X}=84, t_{X}=03\right)=\iint f\left(w \mid C, X, t_{w}=03\right) d F\left(C \mid X, t_{C \mid X}=84\right) d F\left(X \mid t_{X}=03\right) \\
& =\iint f\left(w \mid C, X, t_{w}=03\right) \psi_{C \mid X}(C, X) d F\left(C \mid X, t_{C \mid X}=03\right) d F\left(X \mid t_{X}=03\right)
\end{aligned}
$$

where $\psi_{C \mid X}(C, X)$ is a reweighting function to be defined momentarily. Note that except for $\psi_{C \mid X}$, the second line of (A4) is identical to (A2) with $t=03-$ i.e., the adjusted 2003 distribution that we are interested in is equal to the unconditional distribution of earnings in 2003, with observations reweighted by the function $\psi_{C \mid X}$. If we can estimate $\psi_{C \mid X}$, it is straightforward to incorporate it and obtain the counter factual distribution expressed in (A4) by using the observed distribution of wages in 2003.

The reweighting function is defined (identically) as:

$$
\begin{gathered}
\psi_{C \mid X}(C, X) \equiv \frac{d F\left(C \mid X, t_{C \mid X}=84\right)}{d F\left(C \mid X, t_{C \mid X}=03\right)} \\
=C \bullet\left(\frac{\operatorname{Pr}\left(C=1 \mid X, t_{C \mid X}=84\right)}{\operatorname{Pr}\left(C=1 \mid X, t_{C \mid X}=03\right)}\right)+(1-C) \bullet\left(\frac{\operatorname{Pr}\left(C=0 \mid X, t_{C \mid X}=84\right)}{\operatorname{Pr}\left(C=0 \mid X, t_{C \mid X}=03\right)}\right)
\end{gathered}
$$

The first line identity in (A5) is obtained by substituting the expression on the right side into (A4) and canceling-out the denominator. The second line is derived by noting that $C$ only takes the values 0 or 1 , so that: 


$$
d F\left(C \mid X, t_{C \mid X}=t\right) \equiv C \bullet \operatorname{Pr}\left(C=1 \mid X, t_{C \mid X}=t\right)+(1-C) \bullet \operatorname{Pr}\left(C=0 \mid X, t_{C \mid X}=t\right)
$$

The second equality in (A5) follows from the recognition that one term on the right hand side of (A6) will equal zero.

This weight $\psi_{C \mid X}$ represents the change in the probability between 1984 and 2003 that an individual defined by characteristics $X$ is observed either using or not using a computer on the job. The probabilities in (A6) are easily recognized as expressions from standard binary dependent variable models. These conditional probabilities can be obtained by estimating a model such as a probit or logit and then using the fitted values. The logit equation is used for the results reported in this paper. ${ }^{1}$ In particular, I estimate:

$$
\begin{aligned}
\operatorname{Pr}\left(C=1 \mid X, t_{C \mid X}=\right. & t)=\operatorname{pr}(\mu>H(X) \beta)=1-G(H(X) \beta) \\
& =\frac{\exp (-H(X) \beta)}{1+\exp (-H(X) \beta)}
\end{aligned}
$$

to obtain the structure of $C \mid X$ at time $t$, where the cumulative distribution of $\mu$ is a logistic function denoted by G. In (A7), $H(X)$ is a vector function of $X$ designed to capture the conditional relationship being modeled, and $\beta$ is a vector of estimated coefficients (in the simple case applied in this paper, $H$ is fully linear). This equation is estimated for both the 1984 and 2003 samples and the coefficients are retained. The results are used to fit the probabilities in (A5) using the 2003 sample $X$ 's combined with the 1984 coefficients for the numerator and the 2003 coefficients for the denominator. The resulting estimated weights, $\psi_{C \mid X}$, are incorporated into the kernel density estimation or into the tabulation of distributional statistics, through multiplication of the sampling weights by these estimated counter-factual weights.

\footnotetext{
${ }^{1}$ DFL used probit equations. I use logits because the underlying distribution function for the logit model has a closed-form representation that may be useful in other settings (see for example Daly and Valletta 2006).
} 


\section{Appendix Table 1. Computer Effect on Wages, Quantile Regressions (Education $=$ Bachelor's Degree or More)}

Panel A: 0-5 Years Experience

$\begin{array}{rllllll}\text { year } & \underline{0.10} & \underline{0.25} & \underline{0.50} & \underline{0.75} & \underline{0.90} & \underline{\text { mean }} \\ 1984 & 0.215 * & 0.200 * * & 0.194 * * & 0.209 * * & 0.188 * * & 0.212 * * \\ 1989 & 0.276 * * & 0.288 * * & 0.195 * * & 0.196 * * & 0.108 & 0.192 * * \\ 1993 & 0.231 * * & 0.276 * * & 0.232 * * & 0.188 * * & 0.142 & 0.232 * * \\ 1997 & 0.224 * * & 0.188 * & 0.173 * * & 0.168 * * & 0.144 & 0.150 * * \\ 2001 & 0.222 * & 0.205 * * & 0.242 * * & 0.207 * * & -0.031 & 0.169 * * \\ 2003 & 0.169 * * & 0.174 * & 0.119 * & 0.196 * * & 0.177 & 0.178 * *\end{array}$

Panel B: 6-15 Years Experience

$\begin{array}{rllllll}\text { year } & \underline{0.10} & \underline{0.25} & \underline{0.50} & \underline{0.75} & \underline{0.90} & \underline{\underline{m e a n}} \\ 1984 & 0.200 * * & 0.165 * * & 0.163 * * & 0.108 * * & 0.119 * * & 0.160 * * \\ 1989 & 0.227 * * & 0.201 * * & 0.171 * * & 0.101 * * & 0.076 & 0.166 * * \\ 1993 & 0.260 * * & 0.317 * * & 0.190 * * & 0.146 * * & 0.080 & 0.195 * * \\ 1997 & 0.201 * * & 0.276 * * & 0.175 * * & 0.035 & -0.046 & 0.148 * * \\ 2001 & 0.167 & 0.155 * * & 0.077 & -0.005 & -0.015 & 0.095 * \\ 2003 & 0.319 * * & 0.370 * * & 0.330 * * & 0.189 * * & 0.130 * & 0.286 * *\end{array}$

Panel C: 16-30 Years Experience

$\begin{array}{rllllll}\text { year } & \underline{0.10} & \underline{0.25} & \underline{0.50} & \underline{0.75} & \underline{0.90} & \underline{\text { mean }} \\ 1984 & 0.188 * * & 0.123 * * & 0.105 * & 0.042 & 0.039 & 0.071 * \\ 1989 & 0.319 * * & 0.268 * * & 0.216 * * & 0.124 * * & 0.068 & 0.202 * * \\ 1993 & 0.328 * * & 0.308 * * & 0.214 * * & 0.151 * * & 0.096 * & 0.240 * * \\ 1997 & 0.369 * * & 0.295 * * & 0.235 * * & 0.186 * * & 0.073 * & 0.237 * * \\ 2001 & 0.383 * * & 0.346 * * & 0.321 * * & 0.239 * * & 0.165 * * & 0.297 * * \\ 2003 & 0.218 * * & 0.223 * * & 0.205 * * & 0.176 * * & 0.043 & 0.200 * *\end{array}$

Panel D: 31+ Years Experience

$\begin{array}{rllllll}\text { year } & \underline{0.10} & \underline{0.25} & \underline{0.50} & \underline{0.75} & \underline{0.90} & \underline{\text { mean }} \\ 1984 & 0.117 & 0.289 * * & 0.129 & 0.039 & 0.000 & 0.113 \\ 1989 & 0.184 & 0.147 & 0.105 & 0.045 & 0.076 & 0.101 \\ 1993 & 0.520 * * & 0.584 * * & 0.281 * * & 0.193 * * & 0.107 & 0.364 * * \\ 1997 & 0.153 & 0.247 * & 0.157 & 0.006 & -0.074 & 0.103 \\ 2001 & 0.583 * * & 0.637 * * & 0.524 * * & 0.328 * * & 0.194 * & 0.463 * * \\ 2003 & 0.420 * * & 0.339 * * & 0.145 * & 0.050 & -0.034 & 0.158 * *\end{array}$

Note: "*" and "**" denote significance at the $5 \%$ and $1 \%$ level, respectively. The control variables are the same as in Table 2, except for the use of a single education dummy (graduate degree) and exclusion of experience-squared. 


\section{Appendix Table 2. Computer Effect on Wages, Quantile Regressions}

(Education $=$ High School Degree or Less)

Panel A: 0-5 Years Experience

$\begin{array}{rllllll}\text { year } & \underline{0.10} & \underline{0.25} & \underline{0.50} & \underline{0.75} & \underline{0.90} & \underline{\text { mean }} \\ 1984 & 0.115 * * & 0.100 * * & 0.127 * * & 0.104 * * & 0.110 & 0.125 * * \\ 1989 & 0.129 * * & 0.129 * * & 0.138 * * & 0.141 * * & 0.152 * * & 0.133 * * \\ 1993 & 0.081 * * & 0.077 * * & 0.143 * * & 0.132 * * & 0.093 & 0.108 * * \\ 1997 & 0.094 * * & 0.090 * * & 0.114 * * & 0.157 * * & 0.111 * & 0.129 * * \\ 2001 & 0.108 & 0.061 & 0.099 * & 0.100 * * & 0.003 & 0.087 * * \\ 2003 & 0.147 * * & 0.082 * * & 0.093 * * & 0.134 * * & 0.191 * & 0.123 * *\end{array}$

Panel B: 6-15 Years Experience

$\begin{array}{rllllll}\text { year } & \underline{0.10} & \underline{0.25} & \underline{0.50} & \underline{0.75} & \underline{0.90} & \underline{\text { mean }} \\ 1984 & 0.263 * * & 0.225 * * & 0.203 * * & 0.170 * * & 0.161 * * & 0.193 * * \\ 1989 & 0.161 * * & 0.189 * * & 0.198 * * & 0.195 * * & 0.153 * * & 0.180 * * \\ 1993 & 0.247 * * & 0.216 * * & 0.197 * * & 0.161 * * & 0.173 * * & 0.208 * * \\ 1997 & 0.167 * * & 0.144 * * & 0.170 * * & 0.136 * * & 0.182 * * & 0.158 * * \\ 2001 & 0.150 * * & 0.111 * * & 0.137 * * & 0.117 * * & 0.142 * * & 0.129 * * \\ 2003 & 0.092 * & 0.124 * * & 0.187 * * & 0.151 * * & 0.131 * & 0.146 * *\end{array}$

Panel C: 16-30 Years Experience

$\begin{array}{rllllll}\text { year } & \underline{0.10} & \underline{0.25} & \underline{0.50} & \underline{0.75} & \underline{0.90} & \underline{\text { mean }} \\ 1984 & 0.192 * * & 0.208 * * & 0.188 * * & 0.169 * * & 0.199 * * & 0.190 * * \\ 1989 & 0.268 * * & 0.260 * * & 0.237 * * & 0.246 * * & 0.227 * * & 0.240 * * \\ 1993 & 0.200 * * & 0.223 * * & 0.260 * * & 0.274 * * & 0.276 * * & 0.246 * * \\ 1997 & 0.207 * * & 0.194 * * & 0.258 * * & 0.261 * * & 0.222 * * & 0.230 * * \\ 2001 & 0.146 * * & 0.171 * * & 0.161 * * & 0.176 * * & 0.135 * * & 0.158 * * \\ 2003 & 0.154 * * & 0.170 * * & 0.179 * * & 0.150 * * & 0.161 * * & 0.160 * *\end{array}$

Panel D: 31+ Years Experience

$\begin{array}{rllllll}\text { year } & \underline{0.10} & \underline{0.25} & \underline{0.50} & \underline{0.75} & \underline{0.90} & \underline{\underline{m e a n}} \\ 1984 & 0.215 * * & 0.184 * * & 0.186 * * & 0.206 * * & 0.187 * * & 0.198 * * \\ 1989 & 0.265 * * & 0.264 * * & 0.252 * * & 0.228 * * & 0.302 * * & 0.261 * * \\ 1993 & 0.222 * * & 0.217 * * & 0.227 * * & 0.187 * * & 0.192 * * & 0.220 * * \\ 1997 & 0.182 * * & 0.223 * * & 0.258 * * & 0.268 * * & 0.281 * * & 0.247 * * \\ 2001 & 0.122 * * & 0.132 * * & 0.172^{* *} & 0.151 * * & 0.168 * & 0.166 * * \\ 2003 & 0.154 * * & 0.196 * * & 0.187 * * & 0.145 * * & 0.112 * * & 0.168 * *\end{array}$

Note: "*" and "**" denote significance at the $5 \%$ and $1 \%$ level, respectively. The control variables are the same as in Table 2, except for the use of a single education dummy (high school degree) and exclusion of experience-squared. 